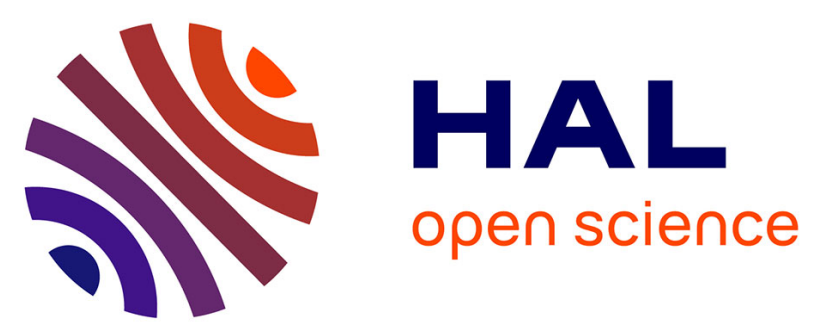

\title{
Nanocatalysts for High Selectivity Enyne Cyclization: Oxidative Surface Reorganization of Gold Sub-2-nm Nanoparticle Networks
}

Houssein Nasrallah, Yuanyuan Min, Emmanuel Lerayer, Tuan-Anh Nguyen, Didier Poinsot, Julien Roger, Stéphane Brandès, Olivier Heintz, Pierre Roblin, Franck Jolibois, et al.

\section{To cite this version:}

Houssein Nasrallah, Yuanyuan Min, Emmanuel Lerayer, Tuan-Anh Nguyen, Didier Poinsot, et al.. Nanocatalysts for High Selectivity Enyne Cyclization: Oxidative Surface Reorganization of Gold Sub2-nm Nanoparticle Networks. JACS Au, 2021, 1 (2), pp.187-200. 10.1021/jacsau.0c00062 . hal03129914

\section{HAL Id: hal-03129914 https://hal.science/hal-03129914}

Submitted on 3 Feb 2021

HAL is a multi-disciplinary open access archive for the deposit and dissemination of scientific research documents, whether they are published or not. The documents may come from teaching and research institutions in France or abroad, or from public or private research centers.
L'archive ouverte pluridisciplinaire HAL, est destinée au dépôt et à la diffusion de documents scientifiques de niveau recherche, publiés ou non, émanant des établissements d'enseignement et de recherche français ou étrangers, des laboratoires publics ou privés. 


\title{
Nanocatalysts for High Selectivity Enyne Cyclization: Oxidative Surface Reorganization of Gold Sub-2-nm Nanoparticle Networks
}

\author{
Houssein O. Nasrallah, Yuanyuan Min, Emmanuel Lerayer, Tuan-Anh Nguyen, Didier Poinsot, \\ Julien Roger, Stéphane Brandès, Olivier Heintz, Pierre Roblin, Franck Jolibois, Romuald Poteau, \\ Yannick Coppel, Myrtil L. Kahn, Iann C. Gerber,* M. Rosa Axet,* Philippe Serp,*
} and Jean-Cyrille Hierso*

Cite This: https://dx.doi.org/10.1021/jacsau.0c00062

Read Online

ABSTRACT: Ultrasmall gold nanoparticles (NPs) stabilized in networks by polymantane ligands (diamondoids) were successfully used as precatalysts for highly selective heterogeneous gold-catalyzed dimethyl allyl(propargyl)malonate cyclization to 5-membered conjugated diene. Such reaction usually suffers from selectivity issues with homogeneous catalysts. This control over selectivity further opened the way to one-pot cascade reaction, as illustrated by the 1,6-enyne cycloisomerization-Diels-Alder reaction of dimethyl allyl propargyl malonate with maleic anhydride. The ability to assemble nanoparticles with controllable sizes and shapes within networks concerns research in sensors, medical diagnostics, information storage, and catalysis applications. Herein, the control of the synthesis of sub-2-nm gold NPs is achieved by the formation of dense networks, which are assembled in a single step reaction by employing ditopic polymantanethiols. By using 1,1'bisadamantane-3,3'-dithiol (BAd-SH) and diamantane-4,9-dithiol (DAd$\mathrm{SH})$, serving both as bulky surface stabilizers and short-sized linkers, we provide a simple method to form uniformly small gold NPs $(1.3 \pm 0.2 \mathrm{~nm}$ to

Polymantanes@Gold Sub-2nm Nanocatalysts

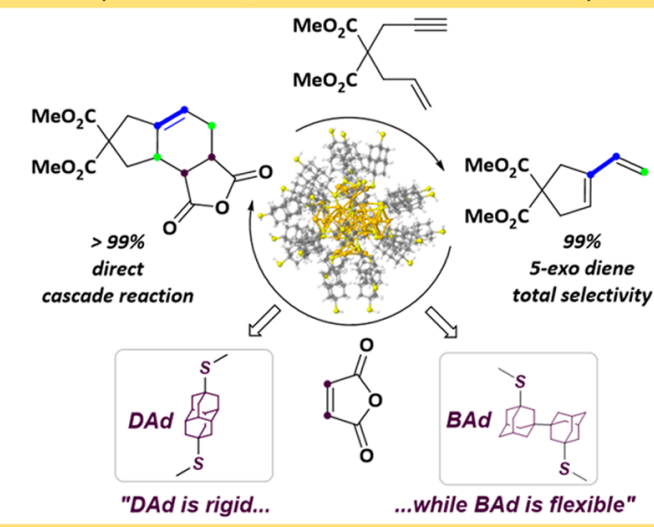

1,6-Enyne Cycloisomerization - Diels-Alder Cascade $1.6 \pm 0.3 \mathrm{~nm}$ ) embedded in rigid frameworks. These NP arrays are organized alongside short interparticular distances ranging from 1.9 to $2.7 \mathrm{~nm}$. The analysis of gold NP surfaces and their modification were achieved in joint experimental and theoretical studies, using notably XPS, NMR, and DFT modeling. Our experimental studies and DFT analyses highlighted the necessary oxidative surface reorganization of individual nanoparticles for an effective enyne cycloisomerization. The modifications at bulky stabilizing ligands allow surface steric decongestion for the alkyne moiety activation but also result in network alteration by overoxidation of sulfurs. Thus, sub-2-nm nanoparticles originating from networks building create convenient conditions for generating reactive $\mathrm{Au}(\mathrm{I})$ surface single-sites-in the absence of silver additives-useful for heterogeneous gold-catalyzed enyne cyclization. These nanocatalysts, which as such ease organic products separation, also provide a convenient access for building further polycyclic complexity, owing to their high reactivity and selectivity.

KEYWORDS: nanocatalysts, enyne cyclization, gold sub-2-nm nanoparticles, diamondoids

\section{INTRODUCTION}

The synthesis and reactivity of gold nanoparticles (NPs) and small-size clusters have been the focus of topical studies because of their size-dependent chemical and electrochemical reactivity, which is useful for a variety of applications. ${ }^{1-7}$ As the NP diameter decreases, their surface area-to-volume ratio $(\mathrm{S} / \mathrm{V})$ increases, leading to vastly different properties and reactivity. ${ }^{8-12}$ Sub-2-nm-sized ${ }^{13,14}$ NPs have attracted great interest since their properties bridge the gap between molecule-like and bulk-like behavior. ${ }^{15-20}$ Nanocatalysts based on ultrasmall NPs and used under heterogeneous conditions are expected to provide new or alternative reactivity and selectivity compared to molecular catalysts, ${ }^{8-14}$ in addition to easier separation of products.

On the other hand, the ability to assemble NPs with controllable sizes and shapes within networks is a current issue which concerns frontier areas of research in sensors, medical diagnostics, information storage, and metal catalysis. ${ }^{21-26}$ In

Received: October 24, 2020 
this context, a challenge is the accurate control of network architectures that conserves nanometer-size for individual NPs. A variety of relevant strategies have been proposed, among which were employed preformed gold colloids with interparticle linking agents such as functionalized polymers and dendrimers, ${ }^{21,22,27}$ multidentate thioether ligands as molecular mediators, $^{23-26}$ or the in situ stabilization of NPs from bidentate sulfides, thiols, or thiolates. ${ }^{28-31}$ The chemical nature of the surface-stabilizing agents and interparticle linkers is crucial for the final structure and properties of the networks and individual NPs. ${ }^{28,32}$ The vast majority of interparticlelinking agents employed are flexible, fairly long, organic molecules. They eventually incorporate polyfunctionalized supramolecular structures based on $s p^{2}$-C-hybridized carbon material, such as fullerenes or cyclodextrins, for instance. ${ }^{33-35}$

Despite this variety of building elements in NP networks construction, the control of dense sub-2-nm NP networks with short interparticular distances in the range of the particle diameter is still lacking. We envisioned that such materials would be of potential interest as nanocatalysts for several reasons: $(i)$ the synthesis of NP networks may be an efficient and simple means for controlling the growth of small particles; (ii) these networks would probably provide additional stability to individual NPs and their surface; (iii) with partial solubility or swelling ability, NP networks may provide interparticular confinement and geometric constraint to adjust selectivity in catalysis, like in MOFs, zeolite, and molecular cavitands. ${ }^{36-41}$

We postulated that the use of short, bulky, rigid interparticle linkers may facilitate the design of such a type of dense NP networks. Mechanically rigid $s p^{3}$-C-hybridized carbon materials, the so-called diamondoids, ${ }^{42-44}$ are essentially hydrogenterminated nanosized diamonds, thermodynamically extremely stable structures. Few adamantane derivatives have been used as $s p^{3}$-C-based building blocks for constructing high-symmetry directional materials. ${ }^{43,46} \mathrm{We}$ investigated herein the use of higher rank polymantanes, i.e. rigid diamantane derivative and more flexible related bis-adamantane, for stabilizing gold NPs. By using ditopic polymantane (or diamondoid) thiol ligands, we provide the conditions for control in weaving dense networks of ultrasmall gold NPs. We achieved DFT modeling of NP structures and network linking by using a $\left[\mathrm{Au}_{38}\right]$ core model decorated with thiol-bisadamantane accounting for sub2-nm gold NPs. The simulation revealed that corner sites are the most favorable for the adsorption of the linking thiols, and, accordingly, the interparticle linkage is achieved from corner to corner. The ultrasmall gold NPs were used as precatalysts for heterogeneous gold-catalyzed dimethyl allyl(propargyl)malonate cyclization, unlike most other catalysts in this enyne-type cyclization in a highly selective manner providing the 5-membered conjugated diene. ${ }^{47-54}$ A surface activation of sub-2-nm gold NP networks is necessary for generating active $\mathrm{Au}(\mathrm{I})$. The resulting nanocatalyst showed an improved and inversed selectivity in the enyne cycloisomerization compared to homogeneous catalysts. DFT investigation focused on the early step of the catalytic process, indicates that the oxidation of the NPs is at the origin of a strong surface reorganization that opens to a less hindered environment around gold, notably by overoxidation of sulfur atoms. Experimental investigations (XPS, TEM, solution and solid state NMR) are in full agreement with computation. This reorganization is needed for the alkyne adsorption and its activation. This reorganization induces an instability of the network but provides specific surface active sites for achieving the selective cycloisomerization. The high selectivity obtained opens the way to further heterogeneous one-pot cascade reactions.

\section{RESULTS AND DISCUSSION}

\section{Functionalized Polymantanes as Surface Stabilizing Ligands and Network Cross-linkers}

In the search for assembling NPs within networks with controllable sizes and shapes, the choice of the organic linker is essential to reach high performance materials, including controlled dimension, high periodicity, and thermal and chemical stability. Adamantane derivatives may favor these essential features. ${ }^{45}$ We selected higher rank ditopic adamantane derivatives (polymantane dithiols) as linkers to control the construction of dense sub-2-nm NPs networks with short interparticle distances. The synthesis of $1,1^{\prime}$-bisadamantane-3,3'-dithiol (BAd-SH) and diamantane-4,9-dithiol (DAd$\mathrm{SH}$ ) was achieved following literature methods (Figure 1). ${ }^{55-57}$

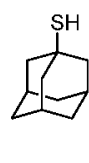

Ad-SH

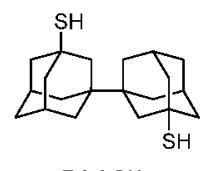

BAd-SH

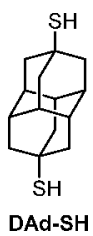

DAd-SH
Figure 1. Surface stabilizing and cross-linking ligands.

For comparative purposes, we also employed 4-aminothiophenol (HATP) and adamantanethiol (Figure 1, Ad-SH) to stabilize the $\mathrm{Au}$ NPs (see details in the Supporting Information (SI), Figures S1-S6 and Schemes S1S2), ${ }^{34,58-62}$ Ad-SH, serving as a pertinent model for the studies, focused on discrete small clusters and NPs. ${ }^{63-66}$

\section{Gold Nanoparticle Network Synthesis and} Characterization

Preliminary studies established that gold NPs are accessible by using adamantanethiol Ad-SH as ligand, which led to small NPs with sizes ranging from $3.3 \pm 0.4 \mathrm{~nm}$ to $1.6 \pm 0.4 \mathrm{~nm}$, depending on the ratio of ligand used. However, the use of polymantanethiols was found to be very profitable in terms of controlling growth size and NP distribution homogeneity (details in SI, Figures S7-S11 and Table S1). This encouraged us to use BAd-SH and DAd-SH in the NP synthesis in the absence of any additional surface stabilizing monodentate ligand (HTAP or Ad-SH). The influence of ligand steric demands on the stabilization of the surface during NPs growth has been studied, ${ }^{28-32}$ and intricate ligand exchanges may involve both stabilizers and linkers. Hence, the synthesis of size-controlled sub-2-nm NP networks was successively achieved in the absence of additional monodentate ligands for surface stabilization. TEM characterizations of gold NP networks assembled by using various ratios of polymantane/ $\mathrm{HAuCl}_{4} \cdot 3 \mathrm{H}_{2} \mathrm{O}$ (i.e. 1.5, 0.5 , and 0.1 equiv related to $\mathrm{HAuCl}_{4} \cdot 3 \mathrm{H}_{2} \mathrm{O}$ ) are illustrated in Figure 2. By using 1.5 equiv of ligand BAd-SH (Figure 2a: BAd-S@AuNPs 150\%) a dense network of NPs with average size around $1.3 \pm 0.2 \mathrm{~nm}$ was obtained, in which a center to center distance of about $2.3 \mathrm{~nm}$ was estimated from TEM images (Figure S11C). A drastic decrease of BAd-SH ligand to 0.5 equiv (Figure 2b: BAd-S@ AuNPs 50\%) or 0.1 equiv (Figure 2c: BAd-S@AuNPs 10\%) led to a progressive growth of the NP size $(1.5 \pm 0.2 \mathrm{~nm}$ and 

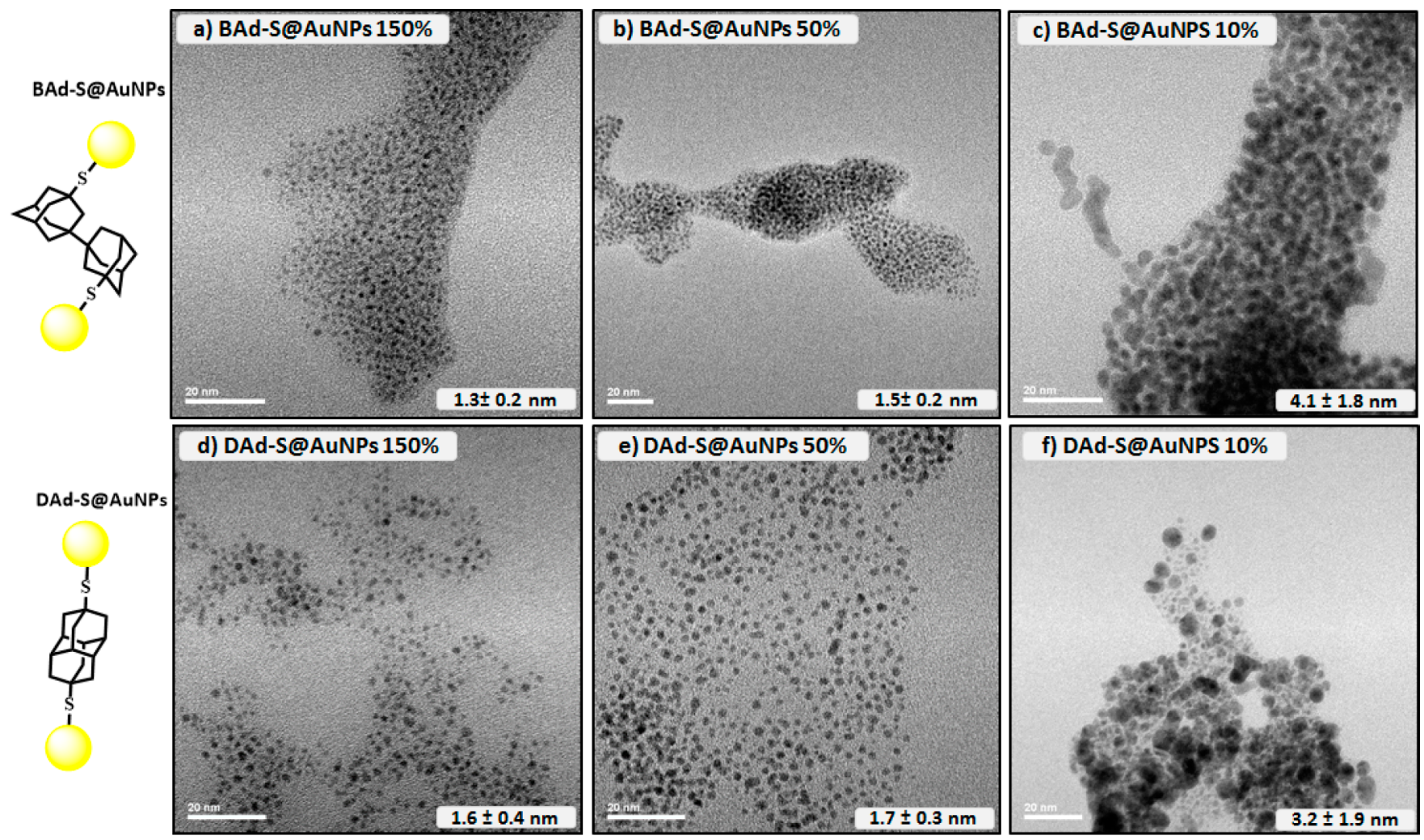

Figure 2. TEM images (scale bar $20 \mathrm{~nm}$ ) of Au NPs stabilized by $1.5(150 \%), 0.5(50 \%)$, and 0.1 (10\%) equiv of BAd-S (a-c) or of DAd-S (d-f).
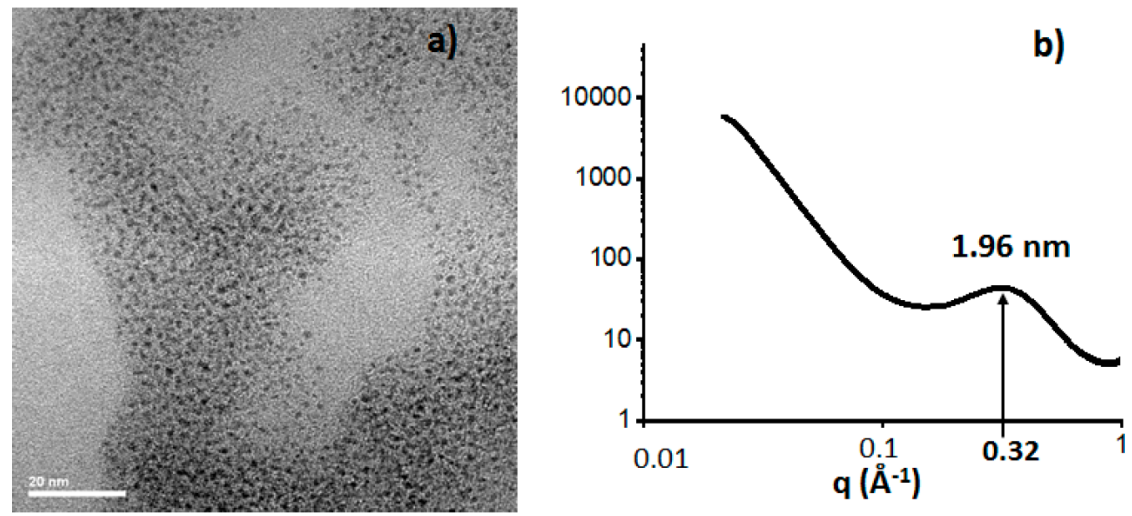

c)

Figure 3. BAd-S@AuNPs 150\%: (a) TEM image (scale bar $20 \mathrm{~nm}$ ), (b) SAXS analysis, and (c) correlated view of the network local dimension using NPs average size (TEM) and the optimized structure of ditopic ligand BAd-SH.

$4.1 \pm 1.8 \mathrm{~nm}$, respectively) accompanied by a detrimental increase of size distribution (Figures S11A, S11B), while the network arrangement is globally conserved. A similar trend was observed from network synthesis by using 1.5 equiv of ligand DAd-SH (Figure 2d: DAd-S@AuNPs 150\%). A homogeneous distribution of NP sized $1.6 \pm 0.4 \mathrm{~nm}$ (as shown in (Figure 2) formed a network with a $2.5 \mathrm{~nm}$ average distance as measured in TEM images (Figure S10C). The use of smaller amounts of ligand DAd-SH (0.5 equiv) was found to markedly decrease the network density (Figure 2e: DAd-S@AuNPs 50\%) while the NP diameter remains $c a .1 .7 \pm 0.3 \mathrm{~nm}$. A 0.1 equiv of DAd$\mathrm{SH}$ was found to be detrimental regarding the formation of ultrasmall size gold particles and their narrow distribution (Figure 2f: DAd-S@AuNPs 10\%, $3.2 \pm 1.9 \mathrm{~nm}$ and Figure S10A). Small angle X-ray scattering (SAXS) analyses were performed on BAd-S@AuNPs 150\% and DAd-S@AuNPs
150\% (Figures 3 and 4 and SI). The scattering intensity profile shows an increase of intensity at smaller $q$ values, which is consistent with a system of dispersed NPs. ${ }^{67}$ At higher $q$ values a clear signal is observed at $0.32 \AA^{-1}$ for BAd-S@AuNPs 150\% (Figure 3b) and $0.25 \AA^{-1}$ for DAd-S@AuNPs 150\% (Figure $4 \mathrm{~b})$. These contributions are attributed to periodic distances existing center to center between the gold NPs. The distance was calculated as $2 \pi / q_{\max }=1.96 \mathrm{~nm}$ for BAd-S@AuNPs $150 \%$ and $2.46 \mathrm{~nm}$ for DAd-S@AuNPs 150\%. These values are consistent with a very dense arrangement of the sub-2-nm gold NPs, which is slightly more compact in the case of BAd-S@ AuNPs 150\% compared to DAd-S@AuNPs 150\%. These values satisfactorily correlate the TEM measurements in which NP interparticle distances were estimated at ca. $2.0-2.3 \mathrm{~nm}$ and $2.5-2.7 \mathrm{~nm}$ (see Figures S11 and S10), respectively. SAXS measurements in the solid state also correlate DFT gas phase 


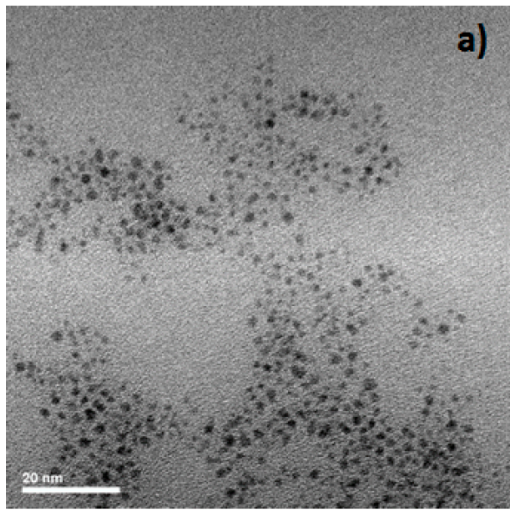

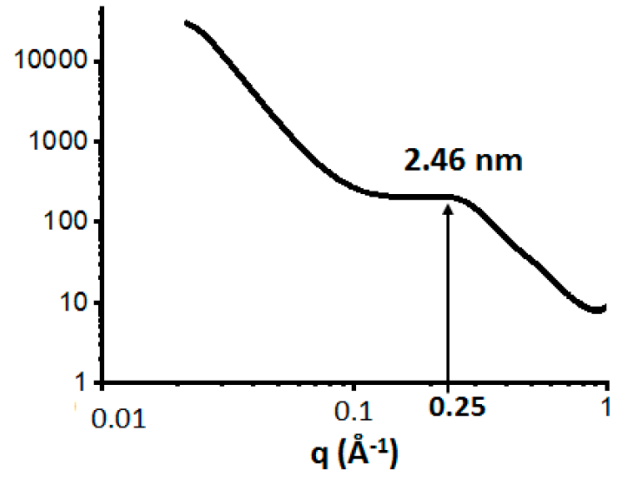

c)

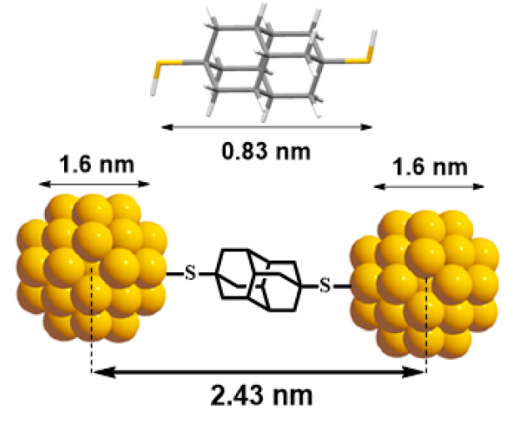

Figure 4. DAd-S@AuNPs 150\%: (a) TEM image (scale bar $20 \mathrm{~nm}$ ), (b) SAXS analysis, and (c) correlated view of the network local dimension using NPs average size (TEM) and the optimized structure of ditopic ligand DAd-SH.

geometry optimization for the ditopic ligands (vide infra). The spatial distance between sulfur atoms in ditopic linker BAd-SH was found ranging between 0.77 and $0.94 \mathrm{~nm}$, depending on the mutual position of the sulfur groups (tuned by rotation around the adamantyl units bond). For the diamantane dithiolate rigid ligand a sulfur separation of $0.83 \mathrm{~nm}$ was calculated. By taking into account the gold NP average diameter size, a consistent network local dimension view is depicted in Figures 3c and 4c.

We examined the interaction between sulfur-functionalized polymantane ligands and gold surfaces by using solution and solid-state NMR. A solid sample of Ad-S@AuNPs 150\% (TEM Figure $\mathrm{S} 8 \mathrm{C}$ ) was dispersed in $\mathrm{CDCl}_{3}$, and the resulting stable colloidal solution of discrete NPs was analyzed by ${ }^{1} \mathrm{H}$ NMR (Figure S12). The coordination of sulfur with gold NPs was confirmed by a significant shift of thiol vicinal protons $\mathrm{H}_{\mathrm{a}}$ from 1.93 to 2.23 ppm in Ad-S@AuNPs 150\% compared with Ad$\mathrm{SH}$. This effect was observed also with tertiary carbon protons $\mathrm{H}_{\mathrm{b}}$, for which a smaller shift was noted from 2.02 to $2.09 \mathrm{ppm}$. This shift is related to an electronic transfer from sulfur to gold surface that was further confirmed by surface photoelectron spectroscopy (see XPS below). The ${ }^{1} \mathrm{H}$ NMR signals for colloidal solutions of Ad-S@AuNPs 150\% were also found to be enlarged, notably for $\mathrm{H}_{\mathrm{a}}$ proximate to the gold surface. These large signals are consistent with the presence of various distinct and structurally related colloidal species. Conversely, the networks based on BAd-SH and DAd-SH were found mostly insoluble or giving unstable colloidal solutions after sonic dispersion; thus, solid-state NMR studies were conducted. As a benchmark, the ${ }^{13} \mathrm{C}$ CP MAS spectrum of Ad-S@AuNPs 50\% NPs was in excellent agreement with that of the Ad-SH ligand alone (Figure S13), with the broadening of the signals in the presence of the NPs also being classical due to structural surface heterogeneity. Consistently, the ${ }^{13} \mathrm{C}$ signals between 42 and $48 \mathrm{ppm}$ were the most broadened by the binding to the Au NP surface since they correspond to carbons proximate to the sulfur atoms coordinated to gold. Moreover, the coordination also induces a slight high frequency shift of these carbon signals. The excellent match between the ${ }^{13} \mathrm{C}$ CP MAS spectrum of the polymantane ligands alone and at the surface of the gold NPs was confirmed with the analysis of BAd-S@AuNPs 50\% (Figures S14 and S16), in which the most affected broadened signals were those around 45-50 ppm. The analysis of the set of NP samples DAd-S@AuNPs 150\%,DAd-S@AuNPs 50\%, and DAd-S@
AuNPs $10 \%$ established a similar surface stabilization with diamantanethiolate (Figures S15 and S17). The signal corresponding to the two apical quaternary sulfur-bonded carbons at $41 \mathrm{ppm}$ is the most impacted in this series and showed a better definition for smaller NPs having a higher ligand content. This corresponds to particles having narrower size distribution, in full agreement with TEM analysis.

X-ray photoelectron spectroscopy (XPS) was performed on BAd-SH and DAd-SH thiols as benchmarks and on NPs networks BAd-S@AuNPs 150\% and DAd-S@AuNPs 150\%. Survey XPS spectra (Figures S18-S20) and high resolution spectra focused on S 2p and $\mathrm{Au} 4 \mathrm{f}$ (Figures S21-S23) indicate that thiolate bonding to gold induces a shift of the $S 2$ p peak at lower energy compared to corresponding thiols $(\Delta=-0.53 \mathrm{eV}$ for BAd-S@AuNPs 150\% and $\Delta=-0.35$ eV for DAd-S@ AuNPs $150 \%)$. The Au $4 \mathrm{f}$ peak is shifted at higher energy compared to metallic bulk $\mathrm{Au}(0)(\Delta=+0.35 \mathrm{eV}$ for BAd-S@ AuNPs and $\Delta=+0.54 \mathrm{eV}$ for DAd-S@AuNPs 150\%). ${ }^{44}$ The $\mathrm{Au}$ 4f core level for BAd-S@AuNPs 150\% and DAd-S@AuNPs $150 \%$ indicated $\mathrm{Au} 4 \mathrm{f}_{7 / 2}$ peaks around 84.6-84.9 eV with a curve fitting into two contributions (Figure 5). $\mathrm{Au} 4 \mathrm{f}_{7 / 2}$ values between 84.0 and $83.5 \mathrm{eV}$ binding energy are attributable to $\mathrm{Au}(0)$ in nanoparticles, ${ }^{68,28-30}$ while higher bonding energy values around $85.0 \mathrm{eV}$ correspond to partly oxidized gold and are observed in the case of $\mathrm{Au}(\mathrm{I})$ surface interaction with thiolate ligands. ${ }^{34}$ Table S2 summarizes bonding energies for curve fitting and the ratio of $\mathrm{Au}(0)$ (located mostly in the bulk) over oxidized gold (located at the NPs surface). For BAd-S@AuNPs 150\% curve fitting of $\mathrm{Au} 4 \mathrm{f}_{7 / 2}$ at $84.6 \mathrm{eV}$ gives a balanced contribution of $\mathrm{Au}(0)(84.2 \mathrm{eV}) / \mathrm{Au}(\mathrm{I})(85.0 \mathrm{eV})$ attributable to gold surface atoms interacting with thiolate groups (Figure 5, 48:52 $\mathrm{Au}^{0} / \mathrm{Au}^{\mathrm{I}}$ ), consistent with ultrasmall sub-2-nm particles (1.3 nm). For DAd-S@AuNPs 150\% a similar trend is observed for $\mathrm{Au} 4 \mathrm{f}_{7 / 2}$ centered at $84.9 \mathrm{eV}$, with a dominant contribution of oxidized gold $(85.1 \mathrm{eV})$ over the core $\mathrm{Au}(0)$ at $84.2 \mathrm{eV}$ (Figure 5, 40:60 $\mathrm{Au}^{0} / \mathrm{Au}^{\mathrm{I}}$ ). ${ }^{69-74}$ This effect is attributed to a stronger electronic influence of diamantyl thiolate. ${ }^{44}$

BAd-SH and DAd-SH both display a S 2 p peak located at $163.5 \mathrm{eV}$, attributed to their thiol function (Table S2 and Figure 6). Comparatively, this peak was shifted to 163.0 and 163.2 eV in BAd-S@AuNPs 150\% and DAd-S@AuNPs 150\%, respectively. This lower binding energy shift is consistent with thiolates attached to the gold surface. The decomposition of the S 2p peak for BAd-S@AuNPs 150\% and DAd-S@AuNPs 

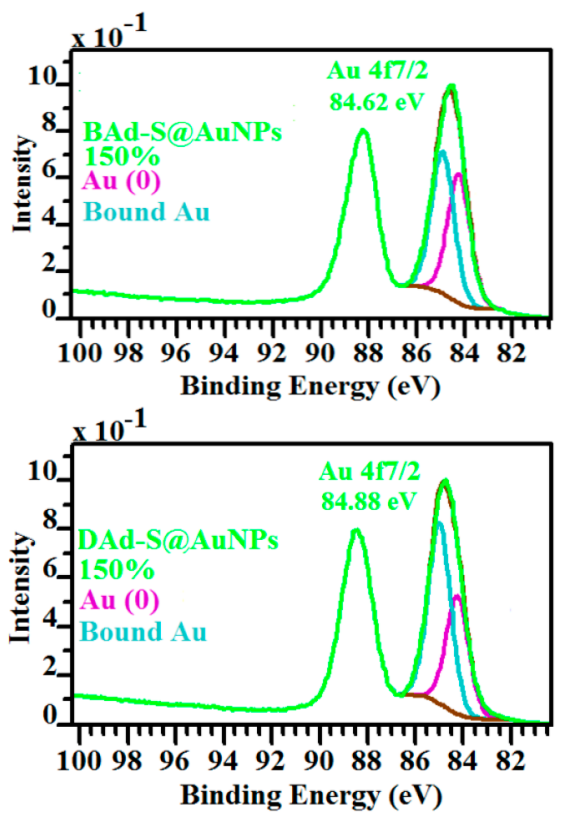

Figure 5. High-resolution XPS spectra at the $\mathrm{Au} 4 \mathrm{f}\left(4 \mathrm{f}_{5 / 2}\right.$ and curve fitting at $\left.4 \mathrm{f}_{7 / 2}\right)$ binding energy of BAd-S@AuNPs 150\% and DAd-S@ AuNPs $150 \%$ (normalized with curve fitting of the $\mathrm{Au} 4 \mathrm{f}_{7 / 2}$ peak).
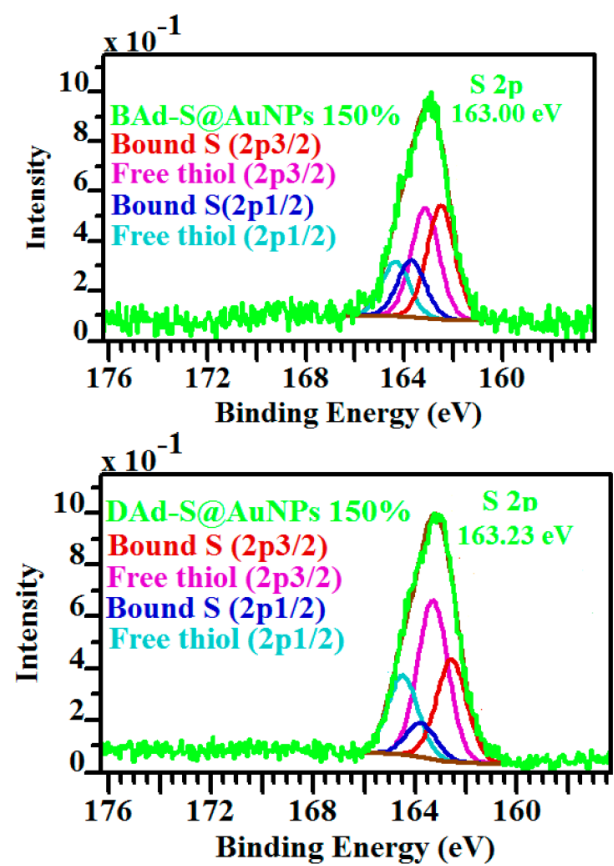

Figure 6. High-resolution XPS spectra at the $S$ 2p binding energy of BAd-S@AuNPs 150\% and DAd-S@AuNPs 150\% (normalized with curve fitting of the $S 2 \mathrm{p}_{3 / 2}$ and $S 2 \mathrm{p}_{1 / 2}$ peaks).

$150 \%$ (Figure 6) fitted a four components attribution in which two peaks $S 2 p_{3 / 2}$ at $162.7 \mathrm{eV}$ and $\mathrm{S} 2 \mathrm{p}_{1 / 2}$ at $163.9 \mathrm{eV}$ are attributed to thiolates attached to the gold surface. In addition, two peaks $\mathrm{S} 2 \mathrm{p}_{3 / 2}(163.3 \mathrm{eV})$ and $\mathrm{S} 2 \mathrm{p}_{1 / 2}(164.5 \mathrm{eV})$ correspond to unbounded thiols, indicating that polymantane ligands serve either as linker or as monodentate stabilizer to NPs. Consistently, DFT analysis (see below) excluded a bidentate coordination of the short-size rigid ligands at a single particle surface, due to unfavorable thermodynamics. The ratio thiolate/thiol indicated that BAd-S is a more suitable linker
(Table S2, ratio thiolate/thiol $=1.04)$ than the more rigid and less easily deprotonated DAd-S (Table S2, ratio thiolate/thiol $=0.54)$. Clearly, as a more flexible linker BAd-S adapts itself more easily to gold NP surfaces during the NP growth process and consequently stabilizes smaller particles in denser networks.

\section{Modeling of Nanoparticle Structures and Network Linking}

We focused our DFT surface modeling studies on the BAd-SH ligand in interaction with gold NPs, in agreement with catalytic performances in selective enyne cycloisomerization (see below). We used a $\left[\mathrm{Au}_{38}\right]$ core for accounting for the experimental sub-2-nm size of gold particles. The optimized structure from Aikens ${ }^{75}$ that appeared to be the most stable structure (see Table S3) was used as the NP model. ${ }^{76}$ This core model presents a length of $1.42 \mathrm{~nm}$ and a width of 1.11 $\mathrm{nm}$, in fairly good agreement with the size of the formed NPs. This core can be almost fully decorated with BAd-S ligands (see Figure 7 for a molecular representation, and the SI for

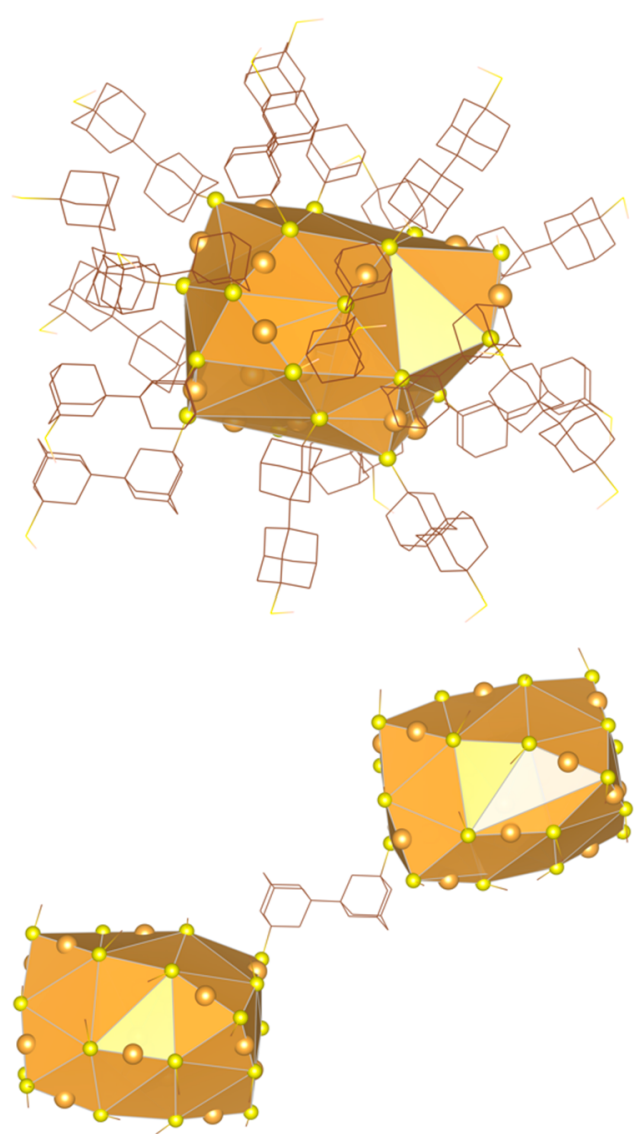

Figure 7. Molecular structure of $\left[\mathrm{Au}_{38}\right]$ NPs with surface stabilized by monoligated polymantane BAd-S (top), and two NPs interparticular bridging corner to corner by BAd-S ditopic linker (bottom), from DFT calculations. Sulfur atoms are yellow, and gold atoms are ocher on the facet and corner sites.

computational details). The thiolates formation from thiols is spontaneously achieved when the $-\mathrm{SH}$ group approaches the gold NP surface.

To estimate the interparticle distance in the networks, we first investigated the favored bonding mode of a single BAd-S group on the $\left[\mathrm{Au}_{38}\right]$ core, and we thereafter determined the most stable configuration when this ligand is bridging two gold nanoparticles. The adsorption of a single BAd-S group on a 
primary model combining a $\left[\mathrm{Au}_{38}\right]$ core saturated by $\mathrm{S}-\mathrm{CH}_{3}$ groups presents three distinct binding sites. Two sites correspond to sulfur atoms at corner gold of the NPs and one at the gold site occupying the middle of the longest facet. The most favorable bonding mode of BAd-S on our model corresponds to corner gold positions (Figure 7). The energy difference for accessing the middle facet gold sites is however fairly weak and inferior to $4 \mathrm{kcal} \mathrm{mol}^{-1}$. For linking two NPs, the most stable configuration is achieved between two sulfur atoms at corner gold sites (Figure 7). Accordingly, the two NP centers are then separated by a distance of $2.34 \mathrm{~nm}$. A facet-tofacet bridging is calculated to be ca. $8 \mathrm{kcal} \mathrm{mol}^{-1}$ higher in energy. This corresponds to NP center-center distances of $1.91 \mathrm{~nm}$, which is in agreement with the distance obtained from SAXS analysis.

To investigate the electronic structures of the NPs fully covered with BAd-S groups, we have considered Bader charges (Figure S24 and Table S4). Gold surface atoms were found to be slightly electron-deficient by an average loss of less than $0.1 \mathrm{e}^{-}$per atom, which is consistent with the XPS analyses. Conversely, the core Au atoms in the "bulk" do not transfer charges (Figure S24 and Table S4). Thus, DFT calculations evidenced the versatility of BAd-S groups in monodentate coordination to nanoparticles, pointing out the role of corner positions for stabilizing the surfaces, without ruling out occasional facet stabilization. The chelation of a BAd-S group at a single gold NP surface in a bidentate coordination was found to be strongly unfavorable. Interparticle linking via sulfur atoms attached to corner and facet sites is feasible, yielding distances which fully correlate with the experimental data.

\section{ICP-AES, Gas Sorption, and Thermogravimetric Analysis}

The gold and sulfur content in the materials was determined by inductively coupled plasma atomic emission spectroscopy (ICP-AES, Figure S25 and Table S5). The sub-2-nm NPs arranged in networks from ditopic BAd-SH and DAd-SH employed at 0.5 and 1.5 equiv incorporate 3.30 to 5.70 wt \% of $\mathrm{S}$, with high gold content between 30 and 45 wt \%, respectively. ${ }^{97}$ Notably, by using 0.5 equiv ( $50 \%$ ligand) and 1.5 equiv of ligand (150\%) the global $\mathrm{Au} / \mathrm{S}$ ratio remains quasi-constant while the ligand amount used was tripled (Figure S25). This confirms that 50\% thiolate ligand is near the threshold of ligand incorporation and that the materials prepared with $150 \%$ equiv are saturated by organic thiolates. This is consistent with the similar NP size and networks obtained when these amounts of ligand are used for synthesis. Gas sorption analyses were achieved by nitrogen adsorption/ desorption experiments at $77 \mathrm{~K}$, and the surface area was determined following the BET method (Figure S26, Table S6). Individual NPs (Ad-S@AuNPs 50\%) formed from adamantanethiol are nonporous $\left(S_{\mathrm{BET}}<13.0 \mathrm{~m}^{2} \mathrm{~g}^{-1}\right)$. Conversely, a significant mesoporosity was observed in the NP networks. The surface area of DAd-S@AuNPs 50\% was found to be $S_{\mathrm{BET}}$ $=55.3 \mathrm{~m}^{2} \mathrm{~g}^{-1}$, and the total mesopore volume $V_{\text {meso }}=0.12 \mathrm{~cm}^{3}$ $\mathrm{g}^{-1}$.

In the case of the BAd-S@AuNPs 50\% network, we observed a lesser $S_{\mathrm{BET}}=18.5 \mathrm{~m}^{2} \mathrm{~g}^{-1}$ with a smaller mesoporosity with $V_{\text {meso }}=0.06 \mathrm{~cm}^{3} \mathrm{~g}^{-1} \cdot 45,78$ Because of its higher rigidity, DAd-S arranges porous NP networks with a higher $S_{\mathrm{BET}}$. The thermogravimetric analysis (TGA, Figure S27) under air indicated that Ad-S@AuNPs 50\% and BAd-S@ AuNPs $50 \%$ are thermally stable up to $100{ }^{\circ} \mathrm{C}$ and gradually decomposed upon temperature increasing, with a better resistance for the BAd-S@AuNPs 50\%. ${ }^{79}$ The gold NP network DAd-S@AuNPs 50\% was found thermally stable up to $400{ }^{\circ} \mathrm{C}$.

\section{Catalytic Studies}

Cycloisomerization of 1,6-enynes is a valuable strategy for the atom-economic synthesis of highly functionalized cyclic structures. $^{47,80}$ Such fine chemistry cyclization presents a great interest to be transferred into heterogeneous conditions since the resulting products give the opportunity to further engage cascade reactions, ${ }^{81-84}$ which is an approach that remains underexploited in heterogeneous catalysis. The reactivity of heterogeneous nanocatalysts in 1,6-enyne metalcatalyzed cyclization is mostly unknown. We assumed that sub2-nm gold particles might be ideal for combining high reactivity and selectivity.

1,6-Enynes cycloisomerization is strongly dependent on the alkene and alkyne connector and on the substituents hold at the alkyne moiety. Several research groups have reported that dimethyl allyl(propargyl)malonate is a specifically challenging substrate in terms of product selectivity. ${ }^{47-52,85-94}$ Under homogeneous conditions, this cyclization gives various mixtures of five- and six-membered dienes A and B (Scheme 1) from cationic $\mathrm{Au}(\mathrm{I})$ Lewis acids obtained via anion

Scheme 1. Selectivity Trends in Gold(I)-Catalyzed Cyclization of Dimethyl Allyl(propargyl)malonate
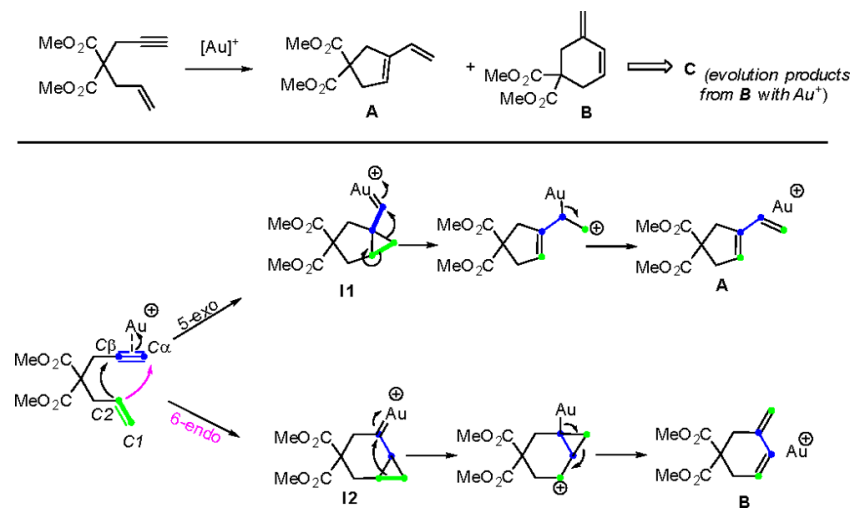

metathesis using silver salts. Conversely, $\mathrm{TiO}_{2}$-supported gold catalysts ( $\mathrm{Au} 1.2 \mathrm{~mol} \%$ ) mostly favored 5-exo cyclization mode to give $A$; unfortunately, the nature of the heterogeneous catalyst is unknown. ${ }^{52}$ The general pathways proposed for the formation of cyclic dienes $\mathbf{A}$ and $\mathbf{B}$ are summarized in Scheme $1 .^{47-52}$ Following the activation of the alkyne, the electrophilic center $C \beta$ of the alkyne is attacked by $C 2$ of the alkene in a 5exo-dig process generating a five-membered cycle ultimately leading to the conjugated diene A.

In the 6-endo-dig process the $C 2$ attacks the $C \alpha$ of the alkyne, which forms the six membered ring of the compound B. Stimulated by these results, we investigated dimethyl allyl(propargyl)malonate cycloisomerization, first under various homogeneous conditions and then using ultrasmall gold NPs stabilized by polymantane ligands under heterogeneous conditions.

\section{Dimethyl Allyl(propargyl)malonate Cyclization from Homogeneous Au(I) Catalysts}

Echavarren et al. achieved intramolecular cycloisomerization of dimethyl allyl(propargyl)malonate by using a catalytic system 
combining $\mathrm{Ph}_{3} \mathrm{PAuCl}$ and $\mathrm{AgSbF}_{6}$ at $0{ }^{\circ} \mathrm{C}$ for a conversion of $77 \%$ with a $1 / 7$ ratio of $\mathbf{A} / \mathbf{B}$ after $20 \mathrm{~min}$ (Table S7, entry 1). ${ }^{48} \mathrm{We}$ confirmed these results and obtained at $20^{\circ} \mathrm{C}$ a total conversion of dimethyl allyl(propargyl)malonate with the same A/B ratio $=1 / 7$ in only 5 min (Table S7, entry 2 ). However, in our hands, over a longer reaction time, this ratio was found to be modified, yielding after $15 \mathrm{~min}$ an $\mathbf{A} / \mathbf{B}$ ratio $=4 / 1$, with the additional formation of side-products in high yield (Figures S28-S31). In their studies of gold-catalyzed intermolecular addition of carbonyl compounds to 1,6-enynes, Helmchen et al. reported that the six-membered diene $\mathbf{B}$ (Scheme 1) was unstable at room temperature and gave rise to unidentified side products (C) in the presence of cationic gold, ${ }^{93}$ possibly polymers. ${ }^{95}$ We also observed the total disappearance of product $\mathrm{B}$ after $2 \mathrm{~h}$ of reaction at $20^{\circ} \mathrm{C}$, with the formation of species difficult to characterize (Table S7, entry 3), ${ }^{93}$ but which formation fully arises from the degradation of $\mathbf{B}$ (see monitoring experiments Figures S29-S31). We also tested a set of molecularly defined ferrocenylphosphine aurophilic digold(I) chloride complexes as homogeneous catalysts (Table S7, entries 4-6) that we previously identified as pertinent cycloisomerization promotors. ${ }^{96,97}$ These catalysts also achieved the rapid ( $5 \mathrm{~min}$ ) but unselective formation of compounds $\mathbf{A}$ and $\mathbf{B}(\mathbf{A} / \mathbf{B}=2 / 1)$, with the latter being found similarly unstable along time. Our approach under homogeneous conditions confirmed that dimethyl allyl(propargyl)malonate is a challenging substrate for selective cycloisomerization, but also because of the high reactivity of $\mathbf{B}$ under the conditions used. This lack of selectivity toward diene $\mathbf{A}$ and the concurrent formation of the unstable diene $\mathbf{B}$ clearly hampered further processing of cascade reactions often accessible in conjugated dienes homogeneous chemistry.

\section{Gold Nanocatalysts for Dimethyl Allyl(propargyl)malonate Cyclization}

Dimethyl allyl(propargyl)malonate cycloisomerization under heterogeneous conditions was tested, using either discrete NPs Ad-S@AuNPs 150\% or sub-2-nm NP networks BAd-S@ AuNPs 50\% and DAd-S@AuNPs 50\% (Au 5 mol \%) in DCE at $70{ }^{\circ} \mathrm{C}$ in the absence of silver salts. No reaction was observed after $16 \mathrm{~h}$. Assuming that catalytically active surface cationic gold(I) species were insufficiently present and/or inaccessible, we achieved further oxidation process on Ad-S@ AuNPs 150\%,BAd-S@AuNPs 50\%, and DAd-S@AuNPs 50\%. The gold NPs were treated with the organic oxidation agents phenyliodine(III) diacetate (PIDA, $\left.70{ }^{\circ} \mathrm{C}, 18 \mathrm{~h}\right)^{98}$ or metachloroperoxybenzoic acid (m-CPBA) $)^{99}$ at $20{ }^{\circ} \mathrm{C}$ for $2 \mathrm{~h}$, avoiding the addition of silver salts. To the best of our knowledge, little is known on the effects of such type of oxidative treatment on thiolated Au NPs. ${ }^{100-108} \mathrm{We}$ analyzed by XPS the resulting materials, as exemplified for the oxidized Ox-DAd-S@AuNPs 50\% (Figure 8). Treatment with m-CPBA was preferred to PIDA because of milder reaction conditions. However, the oxidation was in both cases detrimental for network integrity (see Figures S32 and S33 and the DFT discussion below on the NP surface reorganization).

The comparison of the bonding energy at $S 2 p$ and $\mathrm{Au} 4 f_{7 / 2}$ before and after oxidation is indicative of significant changes at the surface of the NPs. The S 2p peak of DAd-S@AuNPs 50\% initially located at $163.22 \mathrm{eV}$ was strongly shifted to higher energy $(169.86 \mathrm{eV})$ after the oxidation process. This binding energy is attributed to sulfur overoxidation to sulfoxides and sulfones $(\mathrm{SOx}){ }^{74}$ Identical analyses were obtained for $\mathrm{Ox}$ -
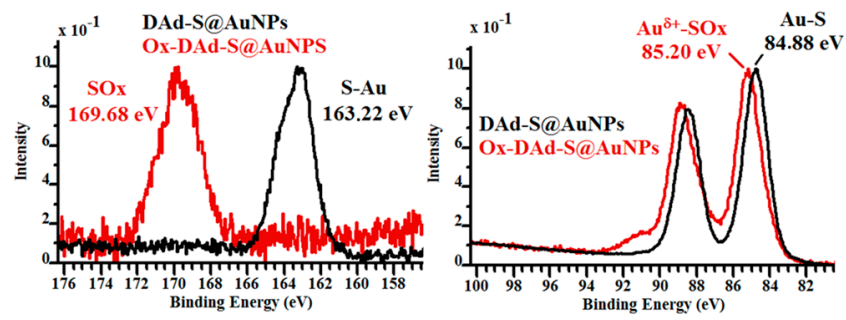

Figure 8. High-resolution XPS spectra (normalized) at the $S$ 2p and $\mathrm{Au}$ 4f binding energies of DAd-S@AuNPs 50\% (black curves) and Ox-DAd-S@AuNPs 50\% (red curves).

BAd-S@AuNPs 50\% (Figure S23). NMR analysis, mass, and DFT (see below) consistently confirmed the sulfur oxidation to $-\mathrm{SO}_{2}$ sulfonyl species for the polymantane ligands.

The Au 4f7/2 shows also a shift about $0.3 \mathrm{eV}$ toward higher binding energy (from 84.9 to $85.2 \mathrm{eV}$ ), which consistently suggests a stronger $\mathrm{Au}(\mathrm{I})$ surface contribution and the presence of cationic gold species. This was also observed in the case of the formation of Ox-BAd-S@AuNPs from BAd-S@ AuNPs (Figure S23). By using these oxidized Au NPs, we achieved cycloisomerization of dimethyl allyl(propargyl)malonate with a full conversion and a total selectivity in the stable diene A (Figure 9 and Figure S34).

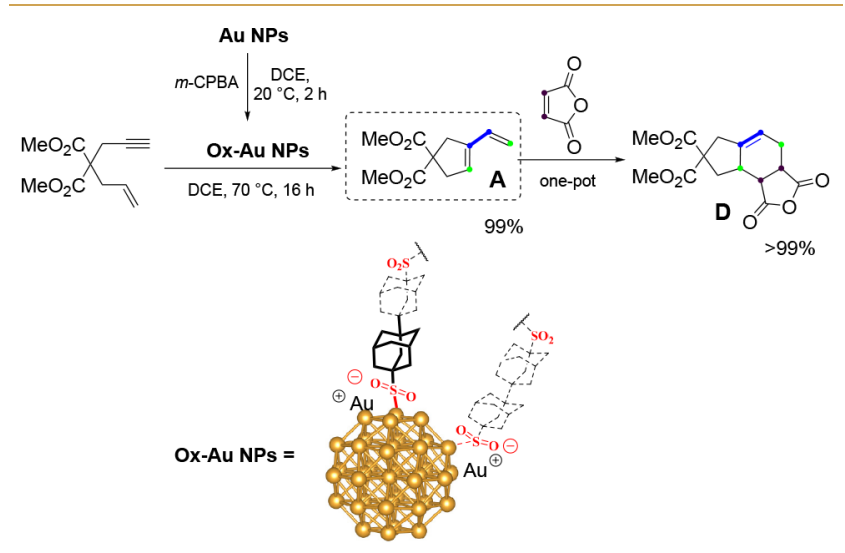

Figure 9. Cycloisomerization of dimethylallyl(propargyl)malonate to A using oxidized gold NPs, and cascade Diels-Alder reaction to D.

Table 1 illustrates the activity of the nanocatalysts. While nonoxidized materials were completely unreactive (entries 13 ), under identical reaction conditions the materials treated with oxidant showed moderate to high activity, pleasingly forming the diene $\mathbf{A}$ with a total selectivity. The gold NPs originally stabilized by adamantanethiolate Ox-Ad-S@AuNPs $150 \%$ led to $20 \%$ conversion in diene A (entry 4). A conversion of 77\% in A was achieved using Ox-Ad-S@AuNPs 50\% (entry 5) while Ox-Ad-S@AuNPs 10\% reached only 30\% conversion (entry 6). The similar high selectivity observed arguably suggests similar cyclization mechanism occurring at the surface of the gold NPs.

Compared to the activity found for the most productive in the adamantyl series (Ox-Ad-S@AuNPs 50\%), the NPs originally prepared as networks from polymantanethiols were found to be more active catalysts. Thus, by using $m$-CPBA in the oxidation step, the resulting Ox-BAd-S@AuNPs 50\% and Ox-DAd-S@AuNPs 50\% gave 99\% and 95\% conversion, respectively (entries 7 and 8 ). The harsher oxidation conditions using PIDA gave no benefit on catalysis (entries 9 
Table 1. Cycloisomerization of Dimethylallyl(propargyl)malonate Using Au NPs Organohybrid Materials ${ }^{a}$

\begin{tabular}{clcc} 
Entry & \multicolumn{1}{c}{ Catalyst } & Conv. (\%) & Selectivity in $\mathbf{A}^{b}$ \\
1 & Ad-S@AuNPs 150\% & 0 & $/$ \\
2 & BAd-S@AuNPs 50\% & 0 & $/$ \\
3 & DAd-S@AuNPs 50\% & 0 & $/$ \\
4 & Ox-Ad-S@AuNPs 150\% & 20 & $>99$ \\
5 & Ox-Ad-S@AuNPs 50\% & 77 & $>99$ \\
6 & Ox-Ad-S@AuNPs 10\% & 30 & $>99$ \\
7 & Ox-BAd-S@AuNPs 50\% & $99^{c}$ & $>99$ \\
8 & Ox-DAd-S@AuNPs 50\% & $95^{c}$ & $>99$ \\
9 & Ox-BAd-S@AuNPs 50\% & $98^{d}$ & $>99$ \\
10 & Ox-DAd-S@AuNPs 50\% & $75^{d}$ & $>99$
\end{tabular}

${ }^{a}$ Conditions: $5 \mathrm{~mol} \% \mathrm{Au}$ total $(2-3.5 \mathrm{~mol} \% \mathrm{Au}$ surface estimation for sub-2-nm NPs depending on shape model), dichloroethane (DCE, $0.09 \mathrm{mmol}$ in substrate), $70{ }^{\circ} \mathrm{C}, 16 \mathrm{~h}$. Conversion and selectivity were determined from ${ }^{1} \mathrm{H}$ NMR in triplicate experiments. ${ }^{b}$ Diene $\mathbf{B}$ is not detected or in trace amounts. ${ }^{\circ}$ Oxidation by $m$-CPBA, $2 \mathrm{~h}$ at $20{ }^{\circ} \mathrm{C}$. ${ }^{d}$ Oxidation by PIDA, $18 \mathrm{~h}$ at $70{ }^{\circ} \mathrm{C}$.

and 10). We obtained similar selectivity but slightly lower activity (60 to 80\%) by using Ox-BAd-S@AuNPs 150\% and Ox-DAd-S@AuNPs 150\%, while conversely the conversion dropped below 50\% by using Ox-BAd-S@AuNPs 10\% and OxDAd-S@AuNPs 10\% analogs.

We achieved several verification experiments using heterogeneous and homogeneous catalysts (Table 2), related to our

Table 2. Cycloisomerization of Dimethylallyl(propargyl)malonate Using Commercially Available $\mathrm{Au} / \mathrm{TiO}_{2}(1 \%)$ and $\mathrm{Au} / \mathrm{C}(5 \%)$ and Thiolate Dinuclear Complexes BAd-S-[ $\left.\mathrm{Au}_{2}\right]$

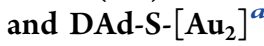

\begin{tabular}{clcc} 
Entry & \multicolumn{1}{c}{ Catalyst } & Conv. (\%) & Selectivity in $\mathbf{A}^{b}$ \\
1 & $\mathrm{Au} / \mathrm{TiO}_{2}$ & 10 & $>99$ \\
2 & $\mathrm{Au} / \mathrm{C}$ & 7 & $>99$ \\
3 & $\mathrm{Ox}-\mathrm{Au} / \mathrm{TiO}_{2}$ & $28^{c}$ & 90 \\
4 & $\mathrm{Ox}-\mathrm{Au} / \mathrm{C}$ & $7^{c}$ & 90 \\
5 & $\mathrm{BAd}-\mathrm{S}-[\mathrm{Au}]_{2}$ & 48 & 82 \\
6 & DAd-S- $[\mathrm{Au}]_{2}$ & 61 & 76
\end{tabular}

${ }^{a}$ Conditions: See Table 1. Conversion and selectivity were determined from ${ }^{1} \mathrm{H}$ NMR in duplicate experiments. ${ }^{b}$ Selectivity decrease is due to the formation of $\mathbf{B}$ and various evolution products (details in the SI). ${ }^{c}$ Oxidation by $m$-CPBA, $2 \mathrm{~h}$ at $20{ }^{\circ} \mathrm{C}$. Thiolate complexes BAd-S-[ $\left.\mathrm{Au}_{2}\right]$ and DAd-S- $\left[\mathrm{Au}_{2}\right]$ were formed from prior thiol deprotonation with triethylamine and further $1: 2 \mathrm{~mol}$ mixture with $\mathrm{ClAuSMe}$. Because of their insolubility in all common organic solvents they were mainly characterized by EA and ICP-AES (Au, S) confirming digold formation per ligand.

present most active and selective systems Ox-BAd-S@AuNPs 50\% and Ox-DAd-S@AuNPs 50\%. In the absence of oxidative treatment, the activities of $\mathrm{Au} / \mathrm{TiO}_{2}$ and $\mathrm{Au} / \mathrm{C}$ were very low at $2 \mathrm{~mol} \%$ catalyst amount in DCE à $70{ }^{\circ} \mathrm{C}$ for $16 \mathrm{~h}$, with an exclusive conversion in $\mathbf{A}$ of $10 \%$ and $7 \%$, respectively (Table 2 , entries 1-2). Compared to polymantane systems, these commercial gold nanocatalysts, similarly treated with $m$-CPBA, also gave significantly lower conversions (respectively $28 \%$ and $7 \%$, entries 4-5) with in addition a decreased selectivity in $\mathbf{A}$ (90\%) because of the formation of unidentified side-products. Notably, compared to homogeneous systems, the selectivity toward $\mathbf{A}$ was also favored from commercial heterogeneous supported gold nanocatalysts.
The use of ditopic ligands BAd-SH and DAd-SH for synthesizing molecular complexes was attempted and found to be very difficult since insoluble products are formed (in chlorocarbons DCM, DCE, chloroform, but also in DMSO, THF, cyclohexane, pentane, heptane, diethyl ether, ethanol, methanol, i-propanol, toluene, etc.) by reacting them with $\mathrm{Au}(\mathrm{I})$ precursor $\mathrm{ClAuSMe}_{2}$, either under thiol conservation conditions (neutral) or thiolate formation conditions (basic), and also either targeting mononuclear or dinuclear complexes. Therefore, the comparison of these ligands used as stabilizing "molecular complexes" is rather uncertain (oligomeric species and mixtures are probably at the origin of the products insolubility). However, thiolate-like complexes BAd-S- $\left[\mathrm{Au}_{2}\right]$ and DAd-S- $\left[\mathrm{Au}_{2}\right]$ can be formed and used as-prepared for catalysis (Table 2, entries 5-6). Clearly, neither the conversion (below 65\%) nor the selectivity for diene A (below 85\%) matches the performances associated with homogeneous systems (Table S7) or heterogeneous polymantane nanocatalysts.

Cascade reactions help build molecular complexity and favor both atom-economy and reduction of waste. ${ }^{\text {109-111 }}$ Gold(I)catalyzed cascade reactions involving activated alkyne have been developed with both nucleophilic and electrophilic reagents, ${ }^{110}$ and cyclization-(hetero)-Diels-Alder tandem reaction can form fused cyclic organic structures. ${ }^{81-84}$ The high selectivity toward the formation of diene $\mathbf{A}$ that was achieved with the polymantane gold NPs gave us the opportunity to further perform a one-pot cascade process based on Diels-Alder reaction. This was achieved by introducing maleic anhydride as additional reagents. Ox-BAdS@AuNPs 50\% and Ox-DAd-S@AuNPs 50\% (5 mol \% Au total) both achieved the 1,6-enyne cycloisomerization-DielsAlder cascade reaction of dimethyl allyl propargyl malonate with maleic anhydride at $70{ }^{\circ} \mathrm{C}(16 \mathrm{~h})$ in DCE and quantitatively provided the tricyclic compound D (Figure 9 and Figures S35 and S36). A related three-component tandem ring closing metathesis-Diels-Alder reaction was reported using a ruthenium catalyst. ${ }^{112,113}$ However, this cascade reaction involving a 5-exo dig 1,6-enyne-cyclization to threefused rings of $\mathbf{D}$ type was not described before using gold(I) catalyst. As the more robust nanocatalyst, Ox-DAd-S@AuNPs $50 \%$ was separated by centrifugation, and reused as such, to quantitatively give compound $\mathbf{D}$ in a second cascade run with the same performance. Postcatalysis TEM analysis of the catalysts did not reveal significant evolution. However, the postoxidation analysis of the NPs (Figures S32 and S33) indicated that this step induces network degradation with gold NP aggregation (10-50 nm). NPs of small size, sub-2-nm, are still present in large amount and are credited for the high reactivity. Consequently, we investigated in more detail the NP surface modification occurring upon oxidation with the help of computational tools, and in relation with effective catalytic reactivity and network degradation.

\section{NP Surface Reorganization for Selective Catalysis}

We used DFT calculations to investigate the initial step of dimethylallyl(propargyl)malonate cycloisomerization, i.e. the necessary substrate coordination to fully decorated gold NPs. Previous related studies by Tang and Zhang concerned DFT calculations detailing mechanistic pathways for dimethyl allyl(propargyl)malonate cycloisomerization selectivity on bare $\left[\mathrm{Au}_{38}\right]$ cluster models. ${ }^{114}$ An approach describing more realistically the present nanocatalysts should include ligand 
interaction with the gold NP surface and thus the alkyne activation process in the presence of the stabilizing ligands $\left(\mathrm{Au}_{38} \mathrm{SL}_{24}\right.$ model $)$. We used an advanced model combining a $\left[\mathrm{Au}_{38}\right]$ core stabilized at saturation with 18 BAd-S groups and six $\mathrm{H}-\mathrm{S}$, which still avoided steric clash, thus accounting for a total number of 968 atoms to describe the NP structure.

On this model of sub-2-nm BAd-S@AuNPs, we originally identified several possible activation sites that correspond to gold atoms already partially oxidized due to their interactions with BAd-S thiolate. Among them, the site we named $\mathrm{Au}(25)$ (Figure 10, top) is of particular interest since it corresponds to

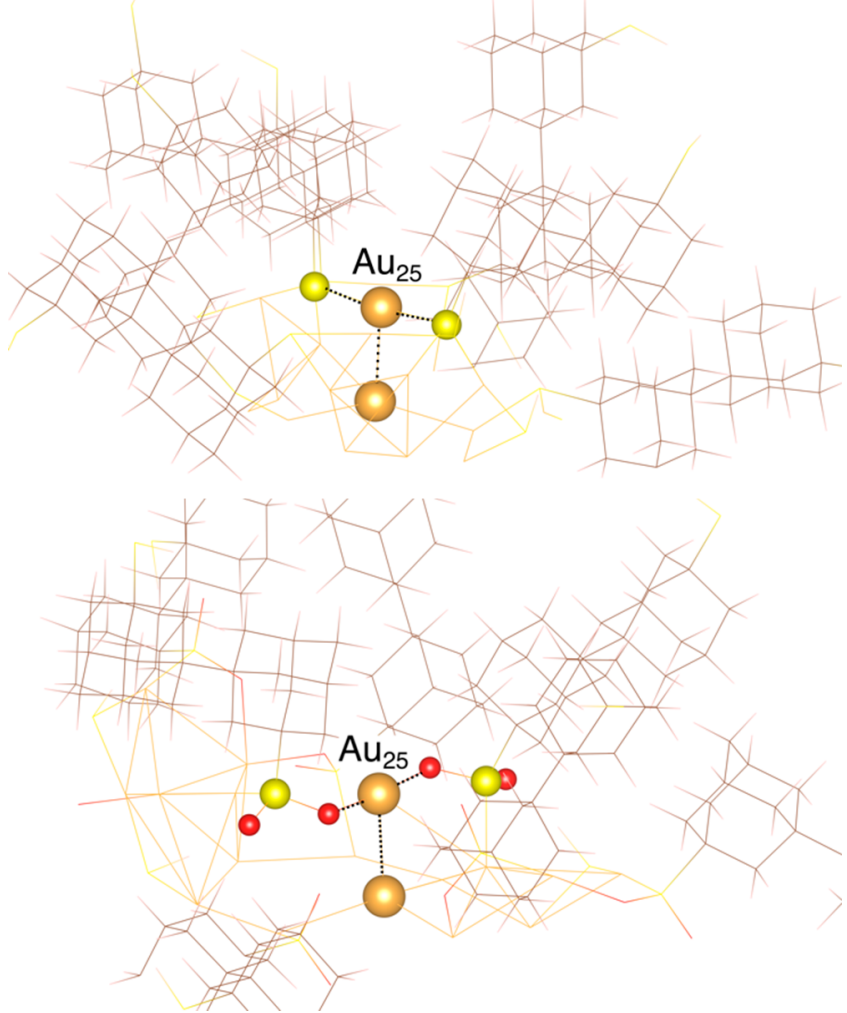

Figure 10. Perspective views of the environment of site $\mathrm{Au}(25)$ in sub-2-nm BAd-S@AuNPs: before (top) and after (bottom) the oxidation process. Gold atoms are in ocher, sulfur in yellow, oxygen in red. The backbone of BAd groups is described as brown lines.

an archetypal gold atom that was pushed out from the NP surface due to the "staple effect". ${ }^{31,115}$ For $\mathrm{Au}(25)$ type sites, only a single nearest $\mathrm{Au}$ atom is found at center to center distances $\mathrm{Au}-\mathrm{Au}=2.93 \AA$, while all other $\mathrm{Au}$ neighbors are located at distances superior to $3.70 \AA$. In addition, $\mathrm{Au}(25)$ also interacts with two sulfur atoms with bond lengths $\mathrm{Au}-\mathrm{S}=$ $2.32 \AA$.

First, in the investigation of NP surface activation of alkynes all our attempts to adsorb the substrate on the stabilized surface of the BAd-S@AuNP model invariably failed. Steric effects added to poor interaction between the substrate and the weakly oxidized gold atoms on the surface always pushed away the dimethylallyl(propargyl)malonate. The DFT local surface approach, in this regard, corroborates the experimental investigation in which no enyne cyclization occurred on the originally formed very stable NP networks.

We thus took into account the oxidation step achieved on the NPs originally formed. A full transformation of BAd-S ligands at the gold surface into $\mathrm{BAd}-\mathrm{SO}_{2}$ sulfonyl species correlated the experimental XPS analysis (Figure 8). As a result, the bare $\mathrm{Au}(25)$ site, which was originally only slightly oxidized with a depletion of 0.1 electron per atom, as indicated in Bader charges analysis (Table S4), further loses electronic density because of its new environment including now two oxygen atoms at short distances, $\mathrm{Au}-\mathrm{O}=2.00 \AA$ (Figure 10, bottom). This also resulted in a shorter distance, $\mathrm{Au}-\mathrm{Au}=$ $2.88 \AA$, with the nearest neighbor. The change within $\mathrm{Au}(25)$ coordination is a major local reorganization of the surface that also opens to a less sterically hindered environment around gold: this by remoteness of the two polymantane fragments attached to the oxidized sulfur atom.

Following this oxidative reorganizing at $\mathrm{Au}(25)$, upon interaction with dimethylallyl(propargyl)malonate, we found a stabilized coordination of the molecule by its alkyne triple bond on this specific gold site (Figure 11a and Figures S37 and S38a).

a)
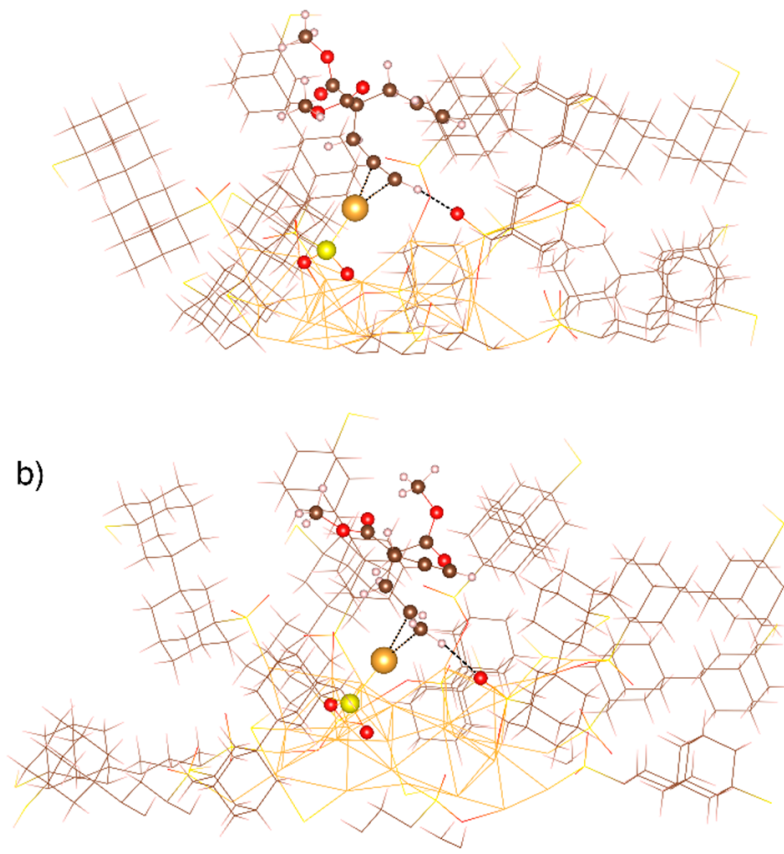

Figure 11. $\mathrm{Au}(25)$ site reorganized in sub-2-nm Ox-BAd-S@AuNPs for coordination of dimethylallyl(propargyl)malonate: (a) adsorption mode by the alkyne $\left(E_{\text {ads }}=-17.9 \mathrm{kcal} \mathrm{mol}^{-1}\right)$, (b) adsorption mode by the olefin $\left(E_{\mathrm{ads}}=-12.9 \mathrm{kcal} \mathrm{mol}^{-1}\right)$. Gold atoms are in ocher, sulfur in yellow, oxygen in red, carbon in brown, hydrogen in gray. The backbone of BAd groups is described as brown lines.

Upon coordination of alkyne, $\mathrm{Au}(25)$ remains attached to a single sulfur atom with a bond length $d \mathrm{Au}-\mathrm{S}=2.30 \AA$, while two $\mathrm{Au}-\mathrm{C}$ bonds $(\mathrm{Au}-\mathrm{C}=2.14$ and $2.30 \AA$ ) are formed and a sulfonyl polymantane ligand leaves the first coordination sphere of $\mathrm{Au}(25)$. The nearest $\mathrm{Au}$ neighbor is now found at a distance of $4.37 \AA$. In this process, the changes in coordination of the sulfonyl polymantanes at $\mathrm{Au}(25)$ from two oxygen atoms (Figure 10, bottom) to a single sulfur (Figure 11) have important consequences: they both open up a supplementary coordination site and decoordinate the second polymantane ligand. The adsorption energy $\left(E_{\mathrm{ads}}\right)$ of this initial step was found at $-17.9 \mathrm{kcal} \mathrm{mol}^{-1}$, in reasonable agreement with calculated values obtained for alkyne adsorption on a free surface of the naked $\left[\mathrm{Au}_{38}\right]$ cluster $\left(-13.4 \mathrm{kcal} \mathrm{mol}^{-1}\right){ }^{114}$ 
Notably, the activation of the alkyne $\mathrm{C} \equiv \mathrm{C}$ triple bond occurs already at this early stage, since a slight increase of the bond length, $d=1.24 \AA$ ( $v s d=1.20 \AA$ for the freestanding molecule), and a $\mathrm{C} \equiv \mathrm{C}-\mathrm{H}$ angle of $164^{\circ}$ are achieved. Interestingly, this angular change (and activation) is also favored by the hydrogen bonding $\mathrm{C}-\mathrm{H} \cdots \mathrm{O}(d=2.00 \AA)$ involving the terminal hydrogen of the alkyne and the oxygen atom of the second remote sulfonyl polymantane initially attached to the $\mathrm{Au}(25)$ site. An important consequence of this reactivity is the loss by release from $\mathrm{Au}(25)$ of a $\mathrm{O}_{2} \mathrm{~S}-$ polymantane ligand, which can reasonably account for gold NP destabilization and network breaking along the course of this reaction. The literature report on calculations from naked $\left[\mathrm{Au}_{38}\right]$ indicated that the adsorption of the substrate via either the triple or double bond was competitive and that bidentate adsorption of the substrate via both the alkyne and olefin groups was also possible. ${ }^{114}$ These two latter situations were also tested on our oxidized $\mathrm{Au}_{38} \mathrm{SL}_{24}$ model, as depicted in Figure 11b (Figure S38b and Figure S38c for bidentate adsorption), and they were not found to be favorable options. Indeed, the adsorption via the olefin double bond is energetically higher $\left(E_{\mathrm{ads}}=-12.9 \mathrm{kcal} \mathrm{mol}^{-1}\right)$ than via the triple bond $\left(E_{\mathrm{ads}}=-17.9 \mathrm{kcal} \mathrm{mol}^{-1}\right)$. The bidentate mode is fully excluded since it yields a positive adsorption energy $E_{\mathrm{ads}}=$ $+3.9 \mathrm{kcal} \mathrm{mol}^{-1}$. By analogy with the general reaction mechanisms proposed (Scheme 1), the favored adsorption mode Figure $11 \mathrm{a}$ corresponds to the starting geometry postulated from the 5-endo cyclization path.

\section{CONCLUSION}

Nanocatalysts based on gold nanoparticles stabilized by polymantane ligands were used for a highly selective enyne cycloisomerization that is not achieved in homogeneous conditions using gold molecular catalysts. The full selectivity reached in cyclization further opens the way to rare heterogeneous one-pot cascade reaction, as illustrated by 1,6enyne cycloisomerization-Diels-Alder reaction of dimethyl allyl propargyl malonate with maleic anhydride. An innovative network formation approach was used for the synthesis of sub2-nm gold NPs (1.3 to $1.6 \mathrm{~nm}$ ), using short-sized rigid ditopic ligands based on functionalized diamondoids, which served as both surface stabilizers and linkers. The analysis of NP and networks formation, and the detailed characterization of gold NP surfaces were achieved in joint experimental and theoretical approaches. DFT modeling of NP structures and network linking was achieved using a $\left[\mathrm{Au}_{38}\right]$ core model fully decorated with bis-adamantanethiol for accounting for the experimental sub-2-nm size of gold particles. Experimental studies and DFT analysis highlighted the necessary oxidative surface reorganization for enyne cycloisomerization. In the initial step of enyne activation, the fluxionality of sulfur and oxygen bonding at gold active sites, from sulfonyl fragments, as well as the presence of alkyne-activating external $\mathrm{C}-\mathrm{H} \cdots \mathrm{O}$ hydrogen bonding is crucial for the activity and selectivity of the gold nanocatalysts.

\section{EXPERIMENTAL SECTION}

\section{Surface Stabilizing Ligands and Network Cross-linkers} (Full Details in SI)

The 1,1'-bisadamantane linker was prepared from homocoupling of 1bromoadamantane using metallic sodium. The $1,1^{\prime}$-bisadamantane$3,3^{\prime}$-diol was synthesized from dibromination followed by hydrolysis.
The diamantane-4,9-diol was achieved from direct oxidation of the commercial diamantane. Both diols were treated by thiourea to obtain the thiouronium salts that were protonated to obtain the corresponding thiols. We also employed 4-aminothiophenol (HATP) and adamantanethiol (Ad-SH) to stabilize Au NPs.

General Procedure for the Preparation of Au NPs (Full Details in the $\mathbf{S I}$ )

Tetrachloroauric acid trihydrate $(20 \mathrm{mg}, 1$ equiv, $51 \mu \mathrm{mol})$ was dissolved in $5 \mathrm{~mL}$ of THF. This mixture and a lithium borohydride solution $(0.20 \mathrm{mmol}, 4$ equiv, $50 \mu \mathrm{L}$ of a $4 \mathrm{M}$ commercial solution, in $5 \mathrm{~mL}$ of THF) were added simultaneously dropwise over $15 \mathrm{~min}$ with two syringes to a $100 \mathrm{~mL}$ two necked round-bottom flask containing a stirred solution of ligand (in $5 \mathrm{~mL}$ THF) at $0{ }^{\circ} \mathrm{C}$. After the end of the addition of $\mathrm{LiBH}_{4}$ and $\mathrm{HAuCl}_{4} \cdot 3 \mathrm{H}_{2} \mathrm{O}$, the mixture was left under stirring vigorously for $5 \mathrm{~h}$ (from $0{ }^{\circ} \mathrm{C}$ to $\mathrm{RT}$ ). For samples with AdSH ligand, THF was removed by rotary evaporation and ethanol was added. The solid was washed with ethanol two times and was collected by centrifugation ( $5 \mathrm{~min}, 5000 \mathrm{rpm}$ ). For the ligands DAd$\mathrm{SH}$ and BAd-SH, the solid materials obtained were washed two times with each solvent successively: THF, ethanol, and dichloromethane, and then dried under vacuum for 30 to $60 \mathrm{~min}$.

\section{Heterogeneous Catalysis}

$\mathrm{Au}$ NPs ( $1 \mathrm{mg}$ of $\mathrm{Au}$, based on ICP analysis) were dispersed in 1.5 $\mathrm{mL}$ of DCE by sonication for $5 \mathrm{~min}$. To this suspension, $15 \mathrm{mg}$ of $\mathrm{m}$ CPBA (0.09 mmol, 17 equiv) was introduced and the reaction mixture was stirred for $2 \mathrm{~h}$ at RT. The oxidized AuNPs were isolated by centrifugation ( $5000 \mathrm{rpm}$ for $2 \mathrm{~min}$ ), rinsed three times by DCE, and used directly in the catalytic tests. The commercial gold nanocatalyst tested references are $\mathrm{Au} / \mathrm{TiO}_{2}$ : Gold $1 \%$ on titanium dioxide extrudates (AUROlite $\mathrm{Au} / \mathrm{TiO}_{2}$ ); CAS: 7440-57-5; Supplier: Strem Chemicals; Supplier ref: 79-0165. URL: https://www.strem. com/catalog/v/79-0165/25/gold_7440-57-5 and Au/C: Gold nanoparticles, $5 \%$ on carbon black (surfactant and reactant-free); CAS: 7440-57-5; Supplier: Strem Chemicals; Supplier ref: 79-0926. URL: https://www.strem.com/catalog/v/79-0926/.

\section{General Instrumentation (Full Details in the $\mathrm{SI}$ )}

XPS experiments were performed with a Versaprobe PHI 5000 apparatus. Transmission electron microscope (TEM) observations were performed on a JEOL JEM-2100F microscope operating at 200 $\mathrm{kV}$. NMR spectra were recorded on a Bruker Avance III 500 spectrometer. Small-angle X-ray scattering (SAXS) was achieved on a Nanostar (Bruker Co) and inductively coupled plasma atomic emission spectroscopy (ICP-AES) on iCAP7400 DUO (ThermoScientific).

\section{DFT Modeling of Nanoparticle Structures and Network} Linking (Full Details in the $\mathrm{SI}$ )

Calculations were performed using the Vienna ab initio simulation package VASP, which employs the full-potential projector augmented waves (PAW) framework. Exchange-correlation effects were approximated using the PBE functional and applied in spin-polarized calculations. Bader charge analysis was used to estimate charge transfer, while VESTA was used to create atomic structure representation. Geometry optimizations were performed using the Gaussian suite of program. The PM6 semiempirical approach was used to obtain a preoptimized structure.

\section{ASSOCIATED CONTENT}

\section{Supporting Information}

The Supporting Information is available free of charge at https://pubs.acs.org/doi/10.1021/jacsau.0c00062.

Detailed experimental procedures, characterization of compounds, full computational details, and complementary data (TEM microscopy, NMR, XPS, ICP, DSC, SAXS, homogeneous and heterogeneous complementary catalysis investigation). (PDF) 


\section{AUTHOR INFORMATION}

\section{Corresponding Authors}

Iann C. Gerber - INSA-CNRS-UPS, LPCNO, Université Fédérale de Toulouse Midi-Pyrénées, F-31077 Toulouse, France; ○ orcid.org/0000-0001-5091-2655;

Email: igerber@insa-toulouse.fr

M. Rosa Axet - LCC-CNRS, Université de Toulouse, INPT, UPS, 31077 Toulouse Cedex 4, France; 이이이.org/00000002-2483-1533; Email: rosa.axet@lcc-toulouse.fr

Philippe Serp - LCC-CNRS, Université de Toulouse, INPT, UPS, 31077 Toulouse Cedex 4, France; (1) orcid.org/00000003-1424-2724; Email: philippe.serp@ensiacet.fr

Jean-Cyrille Hierso - Institut de Chimie Moléculaire de l'Université de Bourgogne (ICMUB - UMR CNRS 6302), Université Bourgogne Franche-Comté (UBFC), 21078 Dijon Cedex, France; 이이.org/0000-0002-2048-647X; Email: jean-cyrille.hierso@u-bourgogne.fr

Authors

Houssein O. Nasrallah - Institut de Chimie Moléculaire de l'Université de Bourgogne (ICMUB - UMR CNRS 6302), Université Bourgogne Franche-Comté (UBFC), 21078 Dijon Cedex, France

Yuanyuan Min - LCC-CNRS, Université de Toulouse, INPT, UPS, 31077 Toulouse Cedex 4, France

Emmanuel Lerayer - Institut de Chimie Moléculaire de l'Université de Bourgogne (ICMUB - UMR CNRS 6302), Université Bourgogne Franche-Comté (UBFC), 21078 Dijon Cedex, France

Tuan-Anh Nguyen - Institut de Chimie Moléculaire de l'Université de Bourgogne (ICMUB - UMR CNRS 6302), Université Bourgogne Franche-Comté (UBFC), 21078 Dijon Cedex, France

Didier Poinsot - Institut de Chimie Moléculaire de l'Université de Bourgogne (ICMUB - UMR CNRS 6302), Université Bourgogne Franche-Comté (UBFC), 21078 Dijon Cedex, France

Julien Roger - Institut de Chimie Moléculaire de l'Université de Bourgogne (ICMUB - UMR CNRS 6302), Université Bourgogne Franche-Comté (UBFC), 21078 Dijon Cedex,

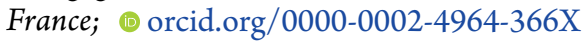

Stéphane Brandès - Institut de Chimie Moléculaire de l'Université de Bourgogne (ICMUB - UMR CNRS 6302), Université Bourgogne Franche-Comté (UBFC), 21078 Dijon Cedex, France; orcid.org/0000-0001-6923-1630

Olivier Heintz - Laboratoire Interdisciplinaire Carnot Bourgogne (ICB - UMR CNRS 6303), Université Bourgogne Franche-Comté (UBFC), Dijon, France

Pierre Roblin - Laboratoire de Génie Chimique and Fédération de Recherche FERMAT, 31030 Toulouse, France

Franck Jolibois - INSA-CNRS-UPS, LPCNO, Université Fédérale de Toulouse Midi-Pyrénées, F-31077 Toulouse, France; (1) orcid.org/0000-0002-2174-4039

Romuald Poteau - INSA-CNRS-UPS, LPCNO, Université Fédérale de Toulouse Midi-Pyrénées, F-31077 Toulouse, France; orcid.org/0000-0003-4338-174X

Yannick Coppel - LCC-CNRS, Université de Toulouse, INPT, UPS, 31077 Toulouse Cedex 4, France; (1) orcid.org/ 0000-0003-0970-4082

Myrtil L. Kahn - LCC-CNRS, Université de Toulouse, INPT, UPS, 31077 Toulouse Cedex 4, France; (1) orcid.org/00000003-3079-5759
Complete contact information is available at: https://pubs.acs.org/10.1021/jacsau.0c00062

\section{Author Contributions}

J.-C.H., P.S., M.R.A., and I.C.G. conceived this program. H.O.N., D.P., and Y.M. synthesized polymantane ligands and gold nanoparticles. H.O.N., E.L., T.-A.N., and J.R. studied gold-catalyzed homogeneous and heterogeneous cycloisomerization and cascade reaction. S.B. achieved BET characterization. O.H. achieved XPS analyses. Y.M. and P.R. achieved SAXS analyses. E.L., Y.C. and M.L.K. achieved NMR surface studies. I.C.G., F.J., and R.P. developed theoretical calculation. J.-C.H., H.O.N., M.R.A., P.S., M.L.K., and I.C.G. wrote the article. All authors valuably contributed to the discussions and approved the final manuscript.

\section{Funding}

This work was supported by the french Agence Nationale de la Recherche (ANR project Icare-1, ANR-16-CE07-0007-01, grant for H.N. and Y.M.), which is gratefully acknowledged. I.C.G. acknowledges the "Calcul en Midi-Pyrénées" initiative CALMIP (Project p0812) for computer time allocation. This work was also granted access to the HPC resources of CINES and IDRIS under the allocation 2019-A0060906649 made by GENCI. In Dijon, the work was supported by the CNRS, the Université de Bourgogne, the Conseil Régional Bourgogne Franche-Comté (CHIMENE project, $\mathrm{PhD}$ grant for T.-A.N.) and the PIA-excellence ISITE-BFC program (COMICS project: Chemistry of Molecular Interactions Catalysis and Sensors; grant for E.L.) and the Fonds Européen de Développement Régional (FEDER).

Notes

The authors declare no competing financial interest.

\section{ACKNOWLEDGMENTS}

Thanks are due to R. Chassagnon for TEM analyses (ICB), M. Heydel for ICP analyses (ICMUB), A. Tsivery for technical support, and P. Fleurat-Lessard for discussions on catalysis mechanisms.

\section{REFERENCES}

(1) Zhang, Y.; Cui, W.; Shi, F.; Deng, Y. Nano-gold catalysis in fine chemical synthesis. Chem. Rev. 2012, 112, 2467.

(2) Hashmi, A.S. K.; Hutchings, G. J. Gold catalysis. Angew. Chem., Int. Ed. 2006, 45, 7896.

(3) Daniel, M.-C.; Astruc, D. Gold nanoparticles: assembly, supramolecular chemistry, quantum-size-related properties, and applications toward biology, catalysis, and nanotechnology. Chem. Rev. 2004, 104, 293.

(4) Murray, R. W. Nanoelectrochemistry: metal nanoparticles, nanoelectrodes, and nanopores. Chem. Rev. 2008, 108, 2688.

(5) Sardar, R.; Funston, A. M.; Mulvaney, P.; Murray, R. W. Gold nanoparticles: past, present, and future. Langmuir 2009, 25, 13840.

(6) Corma, A.; Garcia, H. Supported gold nanoparticles as catalysts for organic reactions. Chem. Soc. Rev. 2008, 37, 2096.

(7) Saha, K.; Agasti, S. S.; Kim, C.; Li, X.; Rotello, V. Gold nanoparticles in chemical and biological sensing. Chem. Rev. 2012, 112, 2739.

(8) Pattadar, D. K.; Zamborini, F. P. Size stability study of catalytically active sub-2 $\mathrm{nm}$ diameter gold nanoparticles synthesized with weak stabilizers. J. Am. Chem. Soc. 2018, 140, 14126.

(9) Miyamura, H.; Min, H.; Soulé, J.-C.; Kobayashi, S. Size of gold nanoparticles driving selective amide synthesis through aerobic condensation of aldehydes and amines. Angew. Chem., Int. Ed. 2015, $54,7564$. 
(10) Zhou, X.; Xu, W.; Liu, G.; Panda, D.; Chen, P. Size-dependent catalytic activity and dynamics of gold nanoparticles at the singlemolecule level. J. Am. Chem. Soc. 2010, 132, 138.

(11) Boronat, M.; Leyva-Perez, A.; Corma, A. Theoretical and Experimental Insights into the Origin of the Catalytic Activity of Subnanometric Gold Clusters: Attempts to Predict Reactivity with Clusters and Nanoparticles of Gold. Acc. Chem. Res. 2014, 47, 834.

(12) Witham, C.; Huang, W.; Tsung, C.; Kuhn, J.; Somorjai, G.; Toste, F. Converting homogeneous to heterogeneous in electrophilic catalysis using monodisperse metal nanoparticles. Nat. Chem. 2010, 2, 36.

(13) Oliver-Meseguer, J.; Cabrero-Antonino, J. R.; Domínguez, I.; Leyva-Pérez, A.; Corma, A. Small Gold Clusters Formed in Solution Give Reaction Turnover Numbers of $10^{7}$ at Room Temperature. Science 2012, 338, 1452.

(14) Hashmi, A. S. K. Sub-Nanosized Gold Catalysts. Science 2012, 338, 1434.

(15) Mistry, H.; Reske, R.; Zeng, Z.; Zhao, Z.-C.; Greeley, J.; Strasser, P.; Cuenya, B. R. Exceptional size-dependent activity enhancement in the electroreduction of $\mathrm{CO}_{2}$ over $\mathrm{Au}$ nanoparticles. J. Am. Chem. Soc. 2014, 136, 16473.

(16) Kauffman, D. R.; Alfonso, D.; Matranga, C.; Qian, H.; Jin, R. Experimental and computational investigation of Au25 clusters and $\mathrm{CO}_{2}$ : a unique interaction and enhanced electrocatalytic activity. $J$. Am. Chem. Soc. 2012, 134, 10237.

(17) Zhu, M.; Aikens, C. M.; Hollander, F. J.; Schatz, G. C.; Jin, R. Correlating the crystal structure of a thiol-protected $\mathrm{Au}_{25}$ cluster and optical properties. J. Am. Chem. Soc. 2008, 130, 5883.

(18) Heaven, M. W.; Dass, A.; White, P. S.; Holt, K. M.; Murray, R.

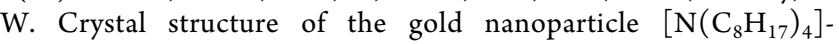
$\left[\mathrm{Au}_{25}\left(\mathrm{SCH}_{2} \mathrm{CH}_{2} \mathrm{Ph}\right)_{18}\right]$. J. Am. Chem. Soc. 2008, 130, 3754.

(19) Ivanova, O. S.; Zamborini, F. P. Size-dependent electrochemical oxidation of silver nanoparticles. J. Am. Chem. Soc. 2010, 132, 70.

(20) Alves, L.; Ballesteros, B.; Boronat, M.; Cabrero-Antonino, J. R.; Concepción, P.; Corma, A.; Correa-Duarte, M. A.; Mendoza, E. Synthesis and stabilization of subnanometric gold oxide nanoparticles on multiwalled carbon nanotubes and their catalytic activity. J. Am. Chem. Soc. 2011, 133, 10251.

(21) Boal, A. K.; Ilhan, F.; DeRouchey, J. E.; Thurn-Albrecht, T.; Russell, T. P.; Rotello, V. M. Self-assembly of nanoparticles into structured spherical and network aggregates. Nature 2000, 404, 746.

(22) Frankamp, B. L.; Boal, A. K.; Rotello, V. M. Controlled interparticle spacing through self-assembly of $\mathrm{Au}$ nanoparticles and poly(amidoamine) dendrimers. J. Am. Chem. Soc. 2002, 124, 15146.

(23) Maye, M. M.; Chun, S. C.; Han, L.; Rabinovich, D.; Zhong, C.J. Novel spherical assembly of gold nanoparticles mediated by a tetradentate thioether. J. Am. Chem. Soc. 2002, 124, 4958.

(24) Maye, M. M.; Luo, J.; Lim, S. I.; Han, L.; Kariuki, N. N.; Rabinovich, D.; Liu, T.; Zhong, C.-J. Size-controlled assembly of gold nanoparticles induced by a tridentate thioether ligand. J. Am. Chem. Soc. 2003, 125, 9906.

(25) Maye, M.; Lim, S. I.; Luo, J.; Rab, Z.; Rabinovich, D.; Liu, T.; Zhong, C.-J. Mediator-template assembly of nanoparticles. J. Am. Chem. Soc. 2005, 127, 1519.

(26) Lim, S. I.; Zhong, C.-J. Molecularly mediated processing and assembly of nanoparticles: exploring the interparticle interactions and structures. Acc. Chem. Res. 2009, 42, 798.

(27) Ye, R.; Zhukhovitskiy, A. V.; Deraedt, C. V.; Toste, F. D.; Somorjai, G. A. Supported dendrimer-encapsulated metal clusters: toward heterogenizing homogeneous catalysts. Acc. Chem. Res. 2017, 50, 1894.

(28) Kanehara, M.; Kodzuka, E.; Teranishi, T. Self-assembly of small gold nanoparticles through interligand interaction. J. Am. Chem. Soc. 2006, 128, 13084.

(29) Teranishi, T.; Haga, M.; Shiozawa, Y.; Miyake, M. SelfOrganization of Au Nanoparticles Protected by 2,6-Bis (1'-(8thiooctyl)benzimidazol-2-yl) pyridine. J. Am. Chem. Soc. 2000, 122, 4237.
(30) Quintiliani, M.; Bassetti, M.; Pasquini, C.; Battocchio, C.; Rossi, M.; Mura, F.; Matassa, R.; Fontana, L.; Russo, M. V.; Fratoddi, I. Network assembly of gold nanoparticles linked through fluorenyl dithiol bridges. J. Mater. Chem. C 2014, 2, 2517.

(31) Heinecke, C. L.; Ni, T. W.; Malola, S.; Mäkinen, V.; Wong, O. A.; Häkkinen, H.; Ackerson, C. J. Structural and theoretical basis for ligand exchange on thiolate monolayer protected gold nanoclusters. $J$. Am. Chem. Soc. 2012, 134, 13316.

(32) Hosier, C. A.; Ackerson, C. J. Regiochemistry of thiolate for selenolate ligand exchange on gold clusters. J. Am. Chem. Soc. 2019, 141, 309.

(33) Liu, J.; Alvarez, J.; Ong, W.; Kaifer, A. E. Network aggregates formed by $\mathrm{C} 60$ and gold nanoparticles capped with $\gamma$-cyclodextrin hosts. Nano Lett. 2001, 1, 57.

(34) Rousseau, G.; Lavenn, C.; Cardenas, L.; Loridant, S.; Wang, Y.; Hahn, U.; Nierengarten, J.-F.; Demessence, A. One-pot synthesis of sub-3 nm gold nanoparticle networks connected by thio-based multidentate fullerene adducts. Chem. Commun. 2015, 51, 6730.

(35) Zhao, Y.; Huang, Y.; Zhu, H.; Zhu, Q.; Xia, Y. Three-in-one: sensing, self-assembly, and cascade catalysis of cyclodextrin modified gold nanoparticles. J. Am. Chem. Soc. 2016, 138, 16645.

(36) Selected examples: Castillejos, E.; Debouttiere, P.-J.; Roiban, L.; Solhy, A.; Martinez, V.; Kihn, Y.; Ersen, O.; Philippot, K.; Chaudret, B.; Serp, P. An efficient strategy to drive nanoparticles into carbon nanotubes and the remarkable effect of confinement on their catalytic performance. Angew. Chem., Int. Ed. 2009, 48, 2529 See also refs $37-41$.

(37) Ding, W.; Wei, Z.; Chen, S.; Qi, X.; Yang, T.; Hu, J.; Wang, D.; Wan, L.-J.; Alvi, S. F.; Li, L. Space-confinement-induced synthesis of pyridinic- and pyrrolic-nitrogen-doped graphene for the catalysis of oxygen reduction. Angew. Chem., Int. Ed. 2013, 52, 11755.

(38) Zhan, B.-Z.; White, M. A.; Sham, T.-K.; Pincock, J. A.; Doucet, R. J.; Rao, K. V. R.; Robertson, K. N.; Cameron, T. S. Zeoliteconfined nano- $\mathrm{RuO}_{2}$ : A green, selective, and efficient catalyst for aerobic alcohol oxidation. J. Am. Chem. Soc. 2003, 125, 2195.

(39) Cho, S.-H.; Ma, B.; Nguyen, S. T.; Hupp, J. T.; AlbrechtSchmitt, T. E. A metal-organic framework material that functions as an enantioselective catalyst for olefin epoxidation. Chem. Commun. 2006, 24, 2563.

(40) Yoshizawa, M.; Takeyama, Y.; Okano, T.; Fujita, M. Cavitydirected synthesis within a self-assembled coordination cage: Highly selective $[2+2]$ cross-photodimerization of olefins. J. Am. Chem. Soc. 2003, 125, 3243 .

(41) Lu, A.-H.; Nitz, J.-J.; Comotti, M.; Weidenthaler, C.; Schlichte, K.; Lehmann, C. W.; Terasaki, O.; Schueth, F. Spatially and size selective synthesis of Fe-based nanoparticles on ordered mesoporous supports as highly active and stable catalysts for ammonia decomposition. J. Am. Chem. Soc. 2010, 132, 14152.

(42) Schwertfeger, H.; Fokin, A. A.; Schreiner, P. R. Diamonds are a chemist's best friend: diamondoid chemistry beyond adamantane. Angew. Chem., Int. Ed. 2008, 47, 1022.

(43) Gunawan, M. A.; Hierso, J.-C.; Poinsot, D.; Fokin, A. A.; Fokina, N. A.; Tkachenko, B. A.; Schreiner, P. R. Diamondoids: functionalization and subsequent applications of perfectly defined molecular cage hydrocarbons. New J. Chem. 2014, 38, 28.

(44) The oxidative electronic effect at the gold surface of NPs stabilized by diamantane thiolate is stronger than with bisadamantane thiolate. Such electronic difference between adamantyl and diamantyl motifs echoes other strong differences between these groups besides their steric resemblance: for instance, primary diamantyl phosphines are surprisingly air stable compared to their adamantyl analogues, partly because of extended sigma hyperconjugation effects of the fused-cage, see: Moncea, O.; Gunawan, M. A.; Poinsot, D.; Cattey, H.; Becker, J.; Yurchenko, R. I.; Butova, E. D.; Hausmann, H.; Šekutor, M.; Fokin, A. A.; Hierso, J.-C.; Schreiner, P. R. Defying Stereotypes with Nanodiamonds: Stable Primary Diamondoid Phosphines. J. Org. Chem. 2016, 81, 8759. 
(45) Nasrallah, H.; Hierso, J.-C. Porous Materials Based on 3Dimensional Td-Directing Functionalized Adamantane Scaffolds and Applied as Recyclable Catalysts. Chem. Mater. 2019, 31, 619.

(46) Min, Y.; Nasrallah, H.; Poinsot, D.; Lecante, P.; Tison, Y.; Martinez, H.; Roblin, P.; Falqui, A.; Poteau, R.; del Rosal, I.; Gerber, I. C.; Hierso, J.-C.; Axet, M. R.; Serp, P. 3D Ruthenium Nanoparticle Covalent Assemblies from Polymantane Ligands for Confined Catalysis. Chem. Mater. 2020, 32, 2365.

(47) Jiménez-Núñez, E.; Echavarren, A. M. Gold-catalyzed cycloisomerizations of enynes: a mechanistic perspective. Chem. Rev. 2008, $108,3326$.

(48) Nieto-Oberhuber, C.; Muñoz, M. P.; Buñuel, E.; Nevado, C.; Cardenas, D. J.; Echavarren, A. M. Cationic gold (I) complexes: highly alkynophilic catalysts for the exo- and endo- cyclization of enynes. Angew. Chem., Int. Ed. 2004, 43, 2402.

(49) Nieto-Oberhuber, C.; Muñoz, M. P.; López, S.; Jiménez-Nuñez, E.; Nevado, C.; Herrero-Gómez, E.; Raducan, M.; Echaverren, A. M. Gold (I)-Catalyzed Cyclizations of 1, 6-Enynes: Alkoxycyclizations and exo/endo Skeletal Rearrangements. Chem.- Eur. J. 2006, 12, 1677.

(50) Zhang, L.; Sun, J.; Kozmin, S. A. Gold and platinum catalysis of enyne cycloisomerization. Adv. Synth. Catal. 2006, 348, 2271.

(51) Nieto-Oberhuber, C.; Pérez-Galán, P.; Herrero-Gómez, E.; Lauterbach, T.; Rodriguez, C.; López, S.; Bour, C.; Rosellón, A.; Cárdenas, D. J.; Echavarren, A. M. Gold (I)-catalyzed intramolecular $[4+2]$ cycloadditions of arylalkynes or 1,3-enynes with alkenes: Scope and mechanism. J. Am. Chem. Soc. 2008, 130, 269.

(52) Gryparis, C.; Efe, C.; Raptis, C.; Lykakis, I. N.; Stratakis, M. Cyclization of 1, 6-Enynes Catalyzed by Gold Nanoparticles Supported on $\mathrm{TiO}_{2}$ : Significant Changes in Selectivity and Mechanism, as Compared to Homogeneous Au-Catalysis. Org. Lett. 2012, 14, 2956.

(53) For the first enyne-type cyclization, see also: Hashmi, A. S. K.; Frost, T. M.; Bats, J. W. Gold Catalysis: On the Phenol Synthesis. Org. Lett. 2001, 3, 3769.

(54) And for the first gold nanoparticle-catalyzed enyne cyclization, see: Carrettin, S.; Blanco, M. C.; Corma, A.; Hashmi, A. S. K. Heterogeneous Gold-Catalysed Synthesis of Phenols. Adv. Synth. Catal. 2006, 348, 1283.

(55) Reinhardt, H. F. Biadamantane and Some of Its Derivatives. J. Org. Chem. 1962, 27, 3258.

(56) Fokina, N. A.; Tkachenko, B. A.; Merz, A.; Serafin, M.; Dahl, J. E. P.; Carlson, R. M. K.; Fokin, A. A.; Schreiner, P. R. Hydroxy Derivatives of Diamantane, Triamantane, and [121] Tetramantane: Selective Preparation of Bis-Apical Derivatives. Eur. J. Org. Chem. 2007, 9, 4738.

(57) Tkachenko, B. A.; Fokina, N. A.; Chernish, L. V.; Dahl, J. E. P.; Carlson, R. M. K.; Fokin, A. A.; Schreiner, P. R. Functionalized nanodiamonds part 3: thiolation of tertiary/bridgehead alcohols. Org. Lett. 2006, 8, 1767.

(58) Gupta, R. K.; Srinivasan, M. P.; Dharmarajan, R. Synthesis of short chain thiol capped gold nanoparticles, their stabilization and immobilization on silicon surface. Colloids Surf., A 2011, 390, 149.

(59) Han, J.; Liu, Y.; Guo, R. Facile synthesis of highly stable gold nanoparticles and their unexpected excellent catalytic activity for Suzuki-Miyaura cross-coupling reaction in water. J. Am. Chem. Soc. 2009, 131, 2060.

(60) Lavenn, C.; Albrieux, F.; Bergeret, G.; Chiriac, R.; Delichere, P.; Tuel, A.; Demessence, A. Functionalized gold magic clusters: $\mathrm{Au}_{25}\left(\mathrm{SPhNH}_{2}\right)_{17}$. Nanoscale 2012, 4, 7334.

(61) Lavenn, C.; Albrieux, F.; Tuel, A.; Demessence, A. Synthesis, characterization and optical properties of an amino-functionalized gold thiolate cluster: $\mathrm{Au}_{10}\left(\mathrm{SPh}-\mathrm{pNH}_{2}\right)_{10}$. J. Colloid Interface Sci. 2014, 418, 234.

(62) Jouyban, A.; Samadi, A.; Khoubnasabjafari, M. A new "turn-on" fluorescent sensor based on gold quantum dots and silver nanoparticles for lamotrigine detection in plasma. Talanta 2017, 172, 126.

(63) Ren, L.; Yuan, P.; Su, H.; Malola, S.; Lin, S.; Tang, Z.; Teo, B. K.; Hakkinen, H.; Zheng, L.; Zheng, N. Bulky surface ligands promote surface reactivities of $\left[\mathrm{Ag}_{141} \mathrm{X}_{12}(\mathrm{~S}-\mathrm{Adm})_{40}\right]^{3+}(\mathrm{X}=\mathrm{Cl}, \mathrm{Br}, \mathrm{I})$ nanoclusters: models for multiple-twinned nanoparticles. J. Am. Chem. Soc. 2017, 139, 13288.

(64) Willey, T. M.; Fabbri, J. D.; Lee, J. R. I.; Schreiner, P. R.; Fokin, A. A.; Tkachenko, B. A.; Fokina, N. A.; Dahl, J. E. P.; Carlson, R. M. K.; Vance, A. L.; Yang, W.; Terminello, L. J.; van Buuren, T.; Melosh, N. A. Near-Edge X-ray Absorption Fine Structure Spectroscopy of Diamondoid Thiol Monolayers on Gold. J. Am. Chem. Soc. 2008, 130, 10536.

(65) Chen, S.; Xiong, L.; Wang, S.; Ma, Z.; Jin, S.; Sheng, H.; Pei, Y.; $\mathrm{Zhu}, \mathrm{M}$. Total Structure Determination of $\mathrm{Au}_{21}(\mathrm{~S}-\mathrm{Adm})_{15}$ and Geometrical/Electronic Structure Evolution of Thiolated Gold Nanoclusters. J. Am. Chem. Soc. 2016, 138, 10754.

(66) Krommenhoek, P. J.; Wang, J.; Hentz, N.; Johnston-Peck, A. C.; Kozek, K. A.; Kalyuzhny, G.; Tracy, J. B. Bulky adamantanethiolate and cyclohexanethiolate ligands favor smaller gold nanoparticles with altered discrete sizes. ACS Nano 2012, 6, 4903.

(67) Leng, F.; Gerber, I. C.; Lecante, P.; Bentaleb, A.; Muñoz, A.; Illescas, B. M.; Martín, M.; Melinte, G.; Ersen, O.; Martinez, H.; Axet, M. R.; Serp, P. Hexakis [60] Fullerene Adduct-Mediated Covalent Assembly of Ruthenium Nanoparticles and Their Catalytic Properties. Chem.-Eur. J. 2017, 23, 13379.

(68) Ye, R.; Zhukhovitskiy, A. V.; Kazantsev, R. V.; Fakra, S. C.; Wickemeyer, B. B.; Toste, F. D.; Somorjai, G. A. Supported Au nanoparticles with $\mathrm{N}$-heterocyclic carbene ligands as active and stable heterogeneous catalysts for lactonization. J. Am. Chem. Soc. 2018, 140, 4144.

(69) For XPS data references concerning $\mathrm{Au}(0), \mathrm{Au}(\mathrm{I})-\mathrm{S}$ thiolate, and $\mathrm{Au}-\mathrm{SO}_{x}$ binding energy, see: Castner, D. G.; Hinds, K.; Grainger, D. W. X-ray Photoelectron Spectroscopy Sulfur $2 p$ Study of Organic Thiol and Disulfide Binding Interactions with Gold Surfaces. Langmuir 1996, 12, 5083 (see also refs 70-74).

(70) Vericat, C.; Vela, M. E.; Benitez, G. A.; Gago, J. M.; Torrelles, X.; Salvarezza, R. C. Surface characterization of sulfur and alkanethiol self-assembled monolayers on $\mathrm{Au}(111)$. J. Phys.: Condens. Matter 2006, 18, R867.

(71) Techane, S. D.; Gamble, L. J.; Castner, D. G. X-ray photoelectron spectroscopy characterization of gold nanoparticles functionalized with amine-terminated alkanethiols. Biointerphases 2011, 6, 98 .

(72) Lustemberg, P. G.; Vericat, C.; Benitez, G. A.; Vela, M. E.; Tognalli, N.; Fainstein, A.; Marciarena, M. L.; Salvarezza, R. C. Spontaneously formed sulfur adlayers on gold in electrolyte solutions: Adsorbed sulfur or gold sulfide? J. Phys. Chem. C 2008, 112, 11394.

(73) Vericat, C.; Vela, M. E.; Benitez, G.; Carro, P.; Salvarezza, R. C. Self-assembled monolayers of thiols and dithiols on gold: new challenges for a well-known system. Chem. Soc. Rev. 2010, 39, 1805. (74) Evans, S. D.; Goppert-Berarducci, K. E.; Urankar, E.; Gerenser, L. J.; Ulman, A.; Snyder, R. G. Monolayers Having Large In-Plane Dipole Moments: Characterization of Sulfone-Containing SelfAssembled Monolayers of Alkanethiols on Gold by FT-IR, XPS and Wetting. Langmuir 1991, 7, 2700.

(75) Lopez-Acevedo, O.; Tsunoyama, H.; Tsukuda, T.; Häkkinen, H.; Aikens, C. M. Chirality and Electronic Structure of the ThiolateProtected $\mathrm{Au}_{38}$ Nanocluster. J. Am. Chem. Soc. 2010, 132, 8210.

(76) Jiang, D.-E.; Luo, W.; Tiago, M. L.; Dai, S. In Search of a Structural Model for a Thiolate-protected $\mathrm{Au}_{38}$ Cluster. J. Phys. Chem. C 2008, 112, 13905.

(77) Gold content in supported/immobilized dispersed NPs is generally below $15 \mathrm{wt} \%$ because of the supporting materials $\left(\mathrm{TiO}_{2}\right.$, dendrimers, cyclodextrines, carbon nanotubes, etc.). In polymantane networks, gold content is in better agreement with hexagonal close packed 2D superlattices of sub-2-nm gold NPs (72-67 Au wt \%); see ref 28. Such compact superlattices were fabricated via a heat-induce annealing process $\left(50{ }^{\circ} \mathrm{C}, 12 \mathrm{~h}\right)$ involving interligand $\pi-\pi$ interactions in a self-assembly process on an amorphous-carboncoated copper grid. 
(78) Bennett, T. D.; Fuchs, A. H.; Cheetham, A. K.; Coudert, F.-X. For mesoporosity see Themed collection in: Flexibility and Disorder in Metal-Organic Frameworks. Dalton Trans. 2016, 45, 4058.

(79) This is consistent with both lower volatility and lesser surface bonding fluxionality of ditopic BAd-S ligand compared to Ad-S.

(80) Hashmi, A. S. K.; Schwarz, L.; Choi, J.-H.; Frost, T. M. A new gold catalyzed C-C bond formation. Angew. Chem., Int. Ed. 2000, 39, 2285.

(81) Barluenga, J.; Calleja, J.; Mendoza, A.; Rodríguez, F.; Fañanás, F. J. Synthesis of Polycyclic Compounds by a Cascade Cycloisomerisation/Diels-Alder Reaction. Chem.-Eur. J. 2010, 16, 7110.

(82) Wang, W.; Dong, S.; Yao, Z.; Feng, L.; Daka, P.; Wang, H.; Xu, $\mathrm{Z}$. Synthesis of spiroaminals and spiroketals with bimetallic relay catalysis. Org. Lett. 2014, 16, 22.

(83) Zhu, S.; Huang, X.; Zhao, T.-Q.; Ma, T.; Jiang, H. Metalcatalyzed formation of 1, 3-cyclohexadienes: a catalyst-dependent reaction. Org. Biomol. Chem. 2015, 13, 1225.

(84) Zhang, S.; Cheng, B.; Wang, S.-A.; Zhou, L.; Tung, C.-H.; Wang, J.; Xu, Z. Gold-Catalyzed Cycloisomerization/1,5-H Migration/Diels-Alder Reaction Cascade: Synthesis of Complex NitrogenContaining Heterocycles. Org. Lett. 2017, 19, 1072.

(85) Jiménez-Núñez, E.; Echavarren, A. M. Molecular diversity through gold catalysis with alkynes. Chem. Commun. 2007, 4, 333.

(86) Fürstner, A.; Davies, P. W. Catalytic carbophilic activation: catalysis by platinum and gold $\pi$ acids. Angew. Chem., Int. Ed. 2007, 46, 3410.

(87) Gorin, D. J.; Toste, F. D. Relativistic effects in homogeneous gold catalysis. Nature 2007, 446, 395.

(88) Michelet, V.; Toullec, P. Y.; Genet, J.-P. Cycloisomerization of 1 , n-enynes: challenging metal-catalyzed rearrangements and mechanistic insights. Angew. Chem., Int. Ed. 2008, 47, 4268.

(89) Soriano, E.; Marco-Contelles, J. Mechanistic insights on the cycloisomerization of polyunsaturated precursors catalyzed by platinum and gold complexes. Acc. Chem. Res. 2009, 42, 1026.

(90) Belmont, P.; Parker, E. Silver and gold catalysis for cycloisomerization reactions. Eur. J. Org. Chem. 2009, 35, 6075.

(91) Shapiro, N. D.; Toste, F. D. A reactivity-driven approach to the discovery and development of gold-catalyzed organic reactions. Synlett 2010, 5, 675 .

(92) Echavarren, A. M.; Jiménez-Núñez, E. Complexity via GoldCatalyzed Molecular Gymnastics. Top. Catal. 2010, 53, 924.

(93) Schelwies, M.; Moser, R.; Dempwolff, A. L.; Rominger, F.; Helmchen, G. Gold-Catalyzed Intermolecular Addition of Carbonyl Compounds to 1,6-Enynes: Reactivity, Scope, and Mechanistic Aspects. Chem. - Eur. J. 2009, 15, 10888.

(94) Schelwies, M.; Dempwolff, A. L.; Rominger, F.; Helmchen, G. Gold-catalyzed intermolecular addition of carbonyl compounds to 1,6-enynes. Angew. Chem., Int. Ed. 2007, 46, 5598.

(95) Such activated alkenes have been reported to provide polymers with typical gold catalysts, see: Hashmi, A. S. K.; Schäfer, S.; Göker, V.; Eisenbach, C. D.; Dirnberger, K.; Zhao-Karger, Z.; Crewdson, P. Gold Catalysis: AuCl-induced Polymerization of Styrene and $n$ Butylvinylether. Aust. J. Chem. 2014, 67, 500.

(96) Nguyen, T.-A.; Roger, J.; Nasrallah, H.; Rampazzi, V.; Fournier, S.; Cattey, H.; Sosa Carrizo, E. D.; Fleurat-Lessard, P.; Devillers, C. H.; Pirio, N.; Lucas, D.; Hierso, J.-C. Gold(I) Complexes Nuclearity in Constrained Ferrocenyl Diphosphines: Dramatic Effect in GoldCatalyzed Enyne Cycloisomerization. Chem. - Asian J. 2020, 15, 2879.

(97) Rampazzi, V.; Roger, J.; Amardeil, R.; Penouilh, M.-J.; Richard, P.; Fleurat-Lessard, P.; Hierso, J.-C. Gold (I) complexes of ferrocenyl polyphosphines: Aurophilic gold chloride formation and phosphineconcerted shuttling of a dinuclear $[\mathrm{ClAu} \cdots \mathrm{AuCl}]$ fragment. Inorg. Chem. 2016, 55, 10907.

(98) Guilbaud, J.; Selmi, A.; Kammoun, M.; Contal, S.; Montalbetti, C.; Pirio, N.; Roger, J.; Hierso, J.-C. C-H Halogenation of Pyridyl Sulfides Avoiding the Sulfur Oxidation: A Direct Catalytic Access to Sulfanyl Polyhalides and Polyaromatics. ACS Omega 2019, 4, 20459.

(99) Guilbaud, J.; Labonde, M.; Selmi, A.; Kammoun, M.; Cattey, H.; Pirio, N.; Roger, J.; Hierso, J.-C. Palladium-Catalyzed Heteroaryl
Thioethers Synthesis Overcoming Palladium Dithiolate Resting States Inertness: Practical Road to Sulfones and NH-Sulfoximines. Catal. Commun. 2018, 111, 52.

(100) For relevant related works, see: Luan, Z.; Salk, T.; Abelson, A.; Jean, S.; Law, M. Reversible Aggregation of Covalently Cross-Linked Gold Nanocrystals by Linker Oxidation. J. Phys. Chem. C 2019, 123, 23643 See also refs 101-108.

(101) Feng, Z.; Velari, S.; Cossaro, A.; Castellarin-Cudia, C.; Verdini, A.; Vesselli, E.; Dri, C.; Peressi, M.; De Vita, A.; Comelli, G. Trapping of Charged Gold Adatoms by Dimethyl Sulfoxide on a Gold Surface. ACS Nano 2015, 9, 8697.

(102) Chauvin, J.-P. R.; Pratt, D. A. On the Reactions of Thiols, Sulfenic Acids, and Sulfinic Acids with Hydrogen Peroxide. Angew. Chem., Int. Ed. 2017, 56, 6255.

(103) Niu, W.; Duan, Y.; Qing, Z.; Huang, H.; Lu, X. Shaping Gold Nanocrystals in Dimethyl Sulfoxide: Toward Trapezohedral and Bipyramidal Nanocrystals Enclosed by $\{311\}$ Facets. J. Am. Chem. Soc. 2017, 139, 5817.

(104) Almukhlifi, H. A.; Burns, R. C. Gold nanoparticles on metal oxide surfaces derived from n-alkanethiolate-stabilized gold nanoparticles; investigations of the adsorption mechanism and sulfate formation during subsequent thermolysis. Appl. Catal., A 2015, 502, 174.

(105) Boronat, M.; Laursen, S.; Leyva-Perez, A.; Oliver-Meseguer, J.; Combita, D.; Corma, A. Partially oxidized gold nanoparticles: A catalytic base-free system for the aerobic homocoupling of alkynes. J. Catal. 2014, 315, 6.

(106) Boronat, M.; Combita, D.; Concepción, P.; Corma, A.; García, H.; Juárez, R.; Laursen, S.; de Dios López-Castro, J. Making C-C Bonds with Gold: Identification of Selective Gold Sites for Homo and Cross-Coupling Reactions between Iodobenzene and Alkynes. J. Phys. Chem. C 2012, 116, 24855.

(107) Jang, Y. H.; Goddard, W. A. Oxidation of Thiol Anchor Groups in Molecular Junction Devices: A Density Functional Theory Study. J. Phys. Chem. C 2010, 114, 4646.

(108) Elliott, E. W., III; Glover, R. D.; Hutchison, J. E. Removal of Thiol Ligands from Surface-Confined Nanoparticles without Particle Growth or Desorption. ACS Nano 2015, 9, 3050.

(109) Nicolaou, K. C.; Edmonds, D. J.; Bulger, P. G. Cascade reactions in total synthesis. Angew. Chem., Int. Ed. 2006, 45, 7134.

(110) Dorel, R.; Echavarren, A. M. Gold (I)-catalyzed activation of alkynes for the construction of molecular complexity. Chem. Rev. 2015, 115, 9028.

(111) Asiri, A. M.; Hashmi, A. S. K. Gold-catalysed reactions of diynes. Chem. Soc. Rev. 2016, 45, 4471.

(112) Lee, H.-Y.; Kim, H. Y.; Tae, H.; Kim, B. G.; Lee, J. One-pot three-component tandem metathesis/Diels-Alder reaction. Org. Lett. 2003, 5, 3439.

(113) Rosillo, M.; Domínguez, G.; Casarrubios, L.; Amador, U.; Pérez-Castells, J. Tandem enyne metathesis-Diels-Alder reaction for construction of natural product frameworks. J. Org. Chem. 2004, 69, 2084.

(114) Tang, D.; Chen, Z.; Tang, Y.; Zhang, J.; Xu, Z.; Zhang, J. Investigation of the Cycloisomerization of 1,6-Enynes Catalyzed by Gold Nanoparticles with First-Principles Calculations: Mechanism and Selectivity. J. Phys. Chem. C 2014, 118, 18510.

(115) Upon interaction with sulfur ligands, the outermost gold shell is lifted outward to form "staple" motifs, see: Li, Y.; Galli, G.; Gygi, F. Electronic structure of thiolate-covered gold nanoparticles: $\mathrm{Au}_{102}(\mathrm{MBA})_{44}$. ACS Nano 2008, 2, 1896. 